\title{
THE EFFECT OF SHIFT STRUCTURE ON PERFORMANCE: THE ROLE OF FATIGUE FOR PARAMEDICS
}

\author{
Tanguy Brachet \\ Guy David \\ Reena Duseja \\ Working Paper 16418 \\ http://www.nber.org/papers/w16418 \\ NATIONAL BUREAU OF ECONOMIC RESEARCH \\ 1050 Massachusetts Avenue \\ Cambridge, MA 02138 \\ September 2010
}

The views expressed herein are those of the authors and do not necessarily reflect the views of the National Bureau of Economic Research.

NBER working papers are circulated for discussion and comment purposes. They have not been peerreviewed or been subject to the review by the NBER Board of Directors that accompanies official NBER publications.

(C) 2010 by Tanguy Brachet, Guy David, and Reena Duseja. All rights reserved. Short sections of text, not to exceed two paragraphs, may be quoted without explicit permission provided that full credit, including $\odot$ notice, is given to the source. 
The Effect of Shift Structure on Performance: The Role of Fatigue for Paramedics

Tanguy Brachet, Guy David, and Reena Duseja

NBER Working Paper No. 16418

September 2010

JEL No. J22,J80,L23

\section{ABSTRACT}

The effect of shift structure on worker performance and productivity is an issue of increasing interest to firms and regulatory bodies. Using approximately 742,000 emergency medical incidents attended by 2,400 paramedics in the state of Mississippi, we evaluate the extent to which paramedics' performance towards the end of their shift is impacted by its length. We find evidence that their performance deteriorates towards the end of long shifts, and argue that fatigue is the mediating factor. These findings have implications for workforce organization, calling attention to regulation designed to limit extended work hours.

Tanguy Brachet

\&KDTON5 LYHUS WRFIDMN

tbrachet@cal.berkeley.edu

Guy David

The Wharton School

University of Pennsylvania

202 Colonial Penn Center

3641 Locust Walk

Philadelphia, PA 19104-6218

and NBER

gdavid2@wharton.upenn.edu
Reena Duseja

Department of Emergency Medicine

1001 Potrero Ave. Building 100. Room 284a

San Francisco, CA 94110

Reena.Duseja@ucsf.edu 


\section{Introduction}

Shift work is common in many industries and is universal in those operating around-the-clock.

Oil, natural gas, pipelines, foundries, steel mills, paper, and printing industries schedule shifts to meet increasing global demand and to take advantage of sophisticated and expensive technology. In other industries, such as media, communications, electric utilities and nuclear power generation, around-the-clock operation and delivery dictates the organization of the workload. Similarly, police and fire departments, emergency rooms, and ambulance services require around-the-clock expert assistance, often on a moment's notice, in situations where lives may be at stake. High degrees of preparedness and service can also be found in just-in-time warehousing, marine and ports services, where employees work in shifts.

Shift work is also common in many industries with less than 24/7 coverage. In manufacturing, continuous processes exist to manage demand fluctuations. For instance, automotive, electronics, semiconductor, and pharmaceutical industries all organize large parts of their labor force into shifts. Similarly, most retailers organize work in shifts. In aviation, public transit, railroads, trucking and shipping, shift work results from extended travel durations and government regulation regarding vehicle operation.

While widespread, the impact of shift structure on performance, productivity, and quality is not well understood. Most firms and organizations function in such a way that labor works in shifts of 12 hours or less on a daily basis, while others have shifts lasting 24 hours or more. Such long 
shifts reduce commuting and adaption time, are associated with longer breaks and time off between consecutive shifts, and by definition, eliminate the practice of back-to-back shifts. On the other hand, the cumulative effect of night work and extended hours can lead to fatigueimpaired employees.

Fatigue from long work hours, sleep deprivation, and circadian disruption have been recognized as substantial causes of serious human errors (Veasey et al. 2002). In the context of health care, policies and procedures aimed at reducing the incidence of medical errors have either been voluntarily implemented by health care organizations or imposed by regulators. In medical education, for example, the Accreditation Council for Graduate Medical Education (ACGME) implemented duty hour restrictions in 2003 for all ACGME-accredited residency programs, following concerns about deaths associated with medical errors in US hospitals (Nasca et al. 2010). ${ }^{1}$ Recent studies have found that extended work hours of health care workers, including residents and nurses, are related to increased medical errors, including more frequent diagnostic errors, and slower completion of procedural tasks (Arnedt et al. 2005). However, there is a paucity of research which isolates fatigue as the mediating factor for deteriorations in performance among health care workers who work extended hours. Quantifying the effect of fatigue resulting from long shifts has important implications for policy and safety regulation design regarding shift structure.

\footnotetext{
${ }^{1}$ In June 2010, the ACGME issued a report calling for an unprecedented 16 hour limit to shift lengths for interns (Nasca et al. 2010).
} 
In this study, we examine the relationship between shift structure and productivity in Emergency Medical Services (EMS), where there is considerable variation in shift structure. Specifically, we analyze paramedic performance in emergent medical and trauma incidents by tracking all paramedics in the state of Mississippi over five years. We first adopt a paramedic fixed-effects difference-in-differences approach and argue that fatigue is likely to be a key contributing factor in the deterioration of paramedic performance toward the end of longer shifts (e.g. a 24 hour shift). We later complement the difference-in-differences analysis with a shift fixed-effects approach when we consider a potential dose-response relationship between time on duty and performance.

The main performance measure in this study is a process measure that is widely accepted in the EMS community, total out-of hospital time, which is measured from the moment the ambulance crew is dispatched to a scene to the moment it arrives at the hospital (Carr et al. 2008). We further partition this measure into response time, on-scene time, and transport time. Response time is the most commonly used performance marker in EMS contracting between municipalities and ambulance providers (David and Brachet, 2009). In addition, we track the number of pre-hospital interventions performed on-scene and minutes-per-procedure.

We find that paramedics working longer shifts exhibit poorer performance toward the end of their shift compared to their own performance when working shorter shifts. In addition, estimating dose-response relationships between duration in shift and performance reveals steep declines in the number of pre-hospital interventions performed in emergent incidents. Given 
the mixed results in the literature regarding the link between shift duration and worker performance, our study contributes to the evidence that performance deteriorates with shift length even in a life-and-death context such as EMS, where there is little room for error. The underlying mechanism is likely fatigue.

\section{Data}

Our data come from the Mississippi Emergency Medical Services Information System (MEMSIS) and are gathered by the Office of Emergency Planning and Response at the Mississippi Department of Health. MEMSIS provides statewide data, systematically collected through a comprehensive software system enabling real time collection of patient level data by EMS providers and dispatchers.

MEMSIS allows us to track the universe of paramedics' activities between 2001 and 2005, totaling 1,625,000 ambulance runs, including inter-facility transfers, in addition to trauma and medical incidents. We limit our attention to EMS incidents for which the initial emergent call was related to trauma (defined as motor vehicle crashes, motorcycle crashes, pedestrian and bicycle injuries, stabbings, assaults, gunshots, or falls) or to a medical emergency (defined as cardiac, gastrointestinal, neurological, psychological/substance abuse, or other) and for which an advanced life support (ALS) unit was dispatched to the scene. ${ }^{2}$ To focus on incidents for which time to definitive care is most likely to be important, we exclude cases of death on arrival

\footnotetext{
${ }^{2}$ ALS units are more heavily equipped than Basic Life Support units, and offer a wider range of interventions on scene.
} 
as well as inter-facility transfers, which are often non-emergent and scheduled in advance. Our final sample is comprised of approximately 150,000 trauma incidents, which involve at least one (of a possible 70) indications of injury and result in emergency transport to a hospital by one of roughly 2,400 paramedics, and approximately 587,000 medical incidents, which involve emergency transport to a hospital.

\section{II.1 Construction of Paramedic Shifts}

MEMSIS, which is designed primarily for monitoring, billing and clinical evaluation, but not for human resources management purposes, does not contain an explicit indicator of shift structure for paramedics. Therefore, we elicit this information from the data. MEMSIS is organized by patient, with each observation corresponding to a single patient, recording the dates and times at which [1] the emergent call was received, [2] an ALS unit was dispatched to the scene, [3] the unit arrived on-scene, [4] the unit left the scene, and [5] the unit delivered the patient to definitive care. For each patient, the paramedic and driver who were dispatched to the incident are identified by unique (and stable) emergency medical technician (EMT) IDs.

We exploit these features and the fact that MEMSIS records every EMS incident in the state whether emergent or not - to construct paramedic and driver shifts based on their periods of inactivity, which we identify by their absences from the data. Sorting the data first by EMT ID, then by date and time at which they were alerted for each incident, we define the beginning of a new shift every time ten or more hours have elapsed between consecutive observations of the 
same paramedic. ${ }^{3}$ Once shifts are defined, we measure a lower bound for the shift's duration as the difference between the times of the first and last calls of the shift. For simplicity, we refer to this difference as "shift length" and plot its distributions in the trauma and medical data on which we focus our analysis in Figures $1 \mathrm{a}$ and 1b, respectively. For both types of incidents, the mode is around nine hours, and the distributions fall off precipitously thereafter, leveling off somewhat around twelve hours. This leveling largely forms the basis for our categorization of shift types: we define long and short shifts as those lasting longer and shorter than twelve hours, respectively. For simplicity, we refer to long shifts as 24 -hour shifts, and short ones as $12-$ hour shifts, though these are admittedly very approximate characterizations.

Figures 1c and 1d plot the distribution of the paramedics' hours of inactivity between shifts, separately for short and long shifts. These distributions are multi-modal, with (local) modes occurring roughly at multiples of twelve hours. Figure 1c indicates that a very large proportion of paramedics on shorter shifts have between twelve and twenty four hours off between shifts. The next highest proportions occur in the $[36,48]$ and $[60,72]$ hours intervals. In turn, those paramedics starting long shifts are considerably more likely to have been off-duty for longer periods, with a large proportion having been inactive between 48 and 72 hours (Figure 1d).

\footnotetext{
${ }^{3}$ For robustness, we used eleven and twelve hours between shifts as cutoffs for defining new shifts. The results presented below were not sensitive to these alternative definitions.
} 
These observations are consistent with evidence that paramedics working 24-hour shifts often have two to three days off between shifts. ${ }^{4}$

Finally, Figures 1e and 1f plot the distribution of the time at which the first incident of a shift occurred, separately for short and long shifts. Whereas the vast majority of first incidents occur between 7AM and 11AM for those paramedics starting long shifts, ${ }^{5}$ the distribution is bimodal among short shifts, with a large mass between 6PM and 9PM. Thus, to provide round-the-clock coverage with short shifts, EMS agencies appear to design an early shift that begins at roughly the same time as those on long shifts, coupled with another that begins in the evening to cover the night. This was also consistent with information collected through interviews with local EMS officials.

The idea behind the ten-hours cutoff is that, given the frequency of incidents in Mississippi, it is unlikely that a paramedic would be on-duty for ten consecutive hours without an incident (these incidents include inter-facility transfers, medical or trauma emergencies, as well as false emergencies). However, this procedure is imperfect as on-duty paramedics may go inactive for ten or more hours, in which case our procedure will assign them a new shift when in fact they

\footnotetext{
${ }^{4}$ The typical 24-hour shift schedule provides approximately 260 days off per calendar year, a reason many paramedics have a preference for this shift structure (Kuehl, 2002). Not surprisingly, a 2006 nationwide survey of paramedics, found more than 55 percent of respondents reported working 24-hour shifts.

${ }^{5}$ In the analysis below, we study only those long shifts for which the first call came in the morning (7AM-12PM), such that the end of the shift roughly coincides with the midnight to $6 \mathrm{AM}$ interval. This corresponds more closely to the clinical literature on the circadian cycle, according to which the natural deterioration in cognition, attention, and focus is most severe between 2AM and 5AM.
} 
are on the same long shift. Thus, we will inappropriately tend to misclassify such paramedics as being on shorter shifts. Should that be the case, our estimates will be attenuated and might be thought of as lower bounds on the effect of long-shifts. Moreover, inactivity is commonly the result of low call volume, which is highly correlated with local characteristics (e.g. population size and density). A second type of misclassification, albeit less likely, may arise if paramedics have breaks between consecutive shifts that last less than ten hours. In this case, we will inappropriately tend to misclassify such paramedics as being on longer shifts. While possible, such instances are not very likely given the structure of shifts in Mississippi (e.g. no agency fits a schedule that consists of three consecutive eight hours shifts)

Nevertheless, it is not conceptually clear that, for the purposes of studying the effects of the variety of fatigue studied here, misclassifications of the first type represent severe threats to validity: while a paramedic may technically be on a long shift, having at least ten hours uninterrupted by an incident implies that she may be well rested for the calls that she does receive (paramedics and EMTs often manage their fatigue with naps). In essence, since the effect that we aspire to identify arises from fatigue that results from sustained wakefulness (rather than chronic fatigue, say), such a paramedic will provide little identifying power if her true shift structure were observable. 


\section{Analysis}

We use a difference-in-differences approach to examine whether shift-to-shift changes in shift structure are associated with changes in underlying paramedic performance during the later segments of their shifts.

In our setting, we conceive of paramedics on long shifts as being in the treatment group and those on short (12 hours or less) shifts as being in the control group. We then define an incident as being treated if it takes place in the last quarter of a paramedic's 24-hour shift. Since the vast majority of 24-hour shifts begin in the morning (see Figure 1f.), it is specifically defined for incidents occurring between midnight and 6AM. This definition captures the intuition that fatigue may manifest itself after long durations on call and especially at night.

There are several reasons to believe that emergent incidents occurring late at night will differ from those occurring during the day. For instance, a motor vehicle accident at 2 AM on a poorly lit county road will likely pose greater difficulties for paramedics than the same accident occurring at mid day. Alternatively, the later accident may be more likely to involve an intoxicated driver, or one who has fallen asleep at the wheel, and is therefore likely to be more severe in both observable and unobservable dimensions. These observations suggest that simple night-versus-day comparisons will be inadequate for studying fatigue, as they will be plagued by unobserved severity and complications. For this reason, the late night deteriorations in performance among paramedics on 24-hour shifts are benchmarked to those of paramedics on 12-hour shifts (who started in the late afternoon/early evening; see Figure 1e.), who experience 
the same changes from day to night in the nature and characteristics of scenes as their 24-hour counterparts.

Our application of difference-in-differences is further refined by the fact that we can identify individual paramedics, allowing us to adopt a paramedic fixed-effects approach. Our estimates therefore result from within-paramedic comparisons, measuring the deterioration in performance that occurs in the last quarter of a paramedic's 24-hour shifts relative to that which he experiences in the second half of his 12-hour evening/night shifts, conditional on observed differences in incident characteristics. The inclusion of paramedic fixed effects implies that our results are not driven by inherent differences between paramedics who are selected for 24-hour shift work and those working shorter shifts. Table 1 indicates that roughly $30 \%$ of both trauma and medical incidents are served by paramedics on 24-hour shifts, and that approximately a quarter of shifts are 24-hour, with a slightly rising trend over time. However, these 24-hour shifts are unequally distributed across provider types. Table 2 indicates that public, fire-based EMS agencies are almost twice more reliant on long shifts compared to hospital-based and private providers, who employ 24-hour shifts between a quarter and a third of the time.

The models we estimate are of the following form:

$$
y_{i s p}=\alpha_{i}+\phi \times 24 \text { HourShift }_{i s}+\beta \times \text { LateNight }_{i s p}+\gamma \times\left(24 \text { HourShift }_{i s} \times \text { LateNight }_{i s p}\right)+\mathbf{X}_{i s p}^{\prime} \Pi+\varepsilon_{i s p}
$$

where $y_{\text {isp }}$ is a measure of performance for paramedic $i$ attending patient $p$ during shift $s$; 24HourShift is is an indicator for whether the attending paramedic is in a 24-hour shift; 
LateNight $t_{\text {isp }}$ indicates whether patient $p^{\prime}$ s call came between midnight and 6AM; $\mathbf{X}_{\text {isp }}$ are incident, patient, and provider characteristics; and $\alpha_{i}$ is a paramedic fixed effect.

We first estimate difference-in-difference models for total out-of-hospital time as the dependent variable, then separately for its component parts, first response, on-scene, and transport times, all of which are common EMS process measures. As additional evidence, we also estimate models using the number of pre-hospital procedures performed on-scene by paramedics, as well as the speed of procedures, conditional on at least one such pre-hospital intervention being performed.

All models control for the certification levels of both drivers and paramedics (indicators for EMT-Driver, EMT-Basic, EMT-Intermediate, EMT-Paramedic), their tenure in years, and their hours of inactivity before the beginning of the current shift. ${ }^{6}$ There are minimum volume restrictions for EMTs to be certified at a higher level, and so the majority of providers in our data switched certification level during their tenure. Moreover, while drivers are less likely to change their certification level (predominantly EMT-Driver), paramedics tend to frequently

\footnotetext{
${ }^{6}$ We do not control for the volume of calls that a paramedic received during a shift leading to the time of each incident to which she was dispatched. While one might argue that fatigue operates not only through sustained wakefulness, but also through the quantity of work she engages in, there are (at least) two arguments against controlling for such a variable. One argument is econometric: there is mechanically limited overlap in the support of this measure between 24-hour and 12-hour shifters, with the former group necessarily accumulating more incidents throughout their longer shifts. For instance, the median call volume for a paramedic in her $20^{\text {th }}$ hour of a 24-hour shift is 6 calls, which is the $90^{\text {th }}$ percentile of call volume for a 12-hour shifter in the last hour of her shift. Controlling for volume would thereby place more of the burden on the linear functional form in the estimation. The second argument is more conceptual. Clearly fatigue can accelerate with call volume, which is itself positively related to duration on duty. Long shifts therefore have a dual effect of forcing paramedics to remain awake for sustained periods and of involving them in more incidents on a per-shift basis. By not controlling for call volume within the shift, we are thus identifying a reduced form parameter that combines these two effects.
} 
switch drivers. Controlling for hours of inactivity before the beginning of the current shift may indicate both alertness level at the beginning of the shift and the paramedic's typical shift structure.

In addition, all models control for patient characteristics (race, age, gender), the type of incident, the incident location (e.g. residence, state/federal highway, etc.), and a series of indicators for year, month, day of week, and hour of the day. We also control for the type (e.g. fracture, burn, laceration, etc) and location (e.g. head, chest, etc) of injury, as well as medical symptoms and 30 indicators for procedures performed on scene. These variables primarily control for the severity of trauma and medical scenes, and insure that the effect of the shift length on performance is not confounded by scene characteristics or by reduced patient severity. In the next section, we provide evidence that paramedics on long shifts are not dispatched to less severe incidents, by showing that paramedics' shift lengths are not correlated with scene characteristics and patient acuity.

In Mississippi, EMS is provided by a network of ambulance services organized at the county or city level. These municipalities contract with EMS providers on a sole-provider basis, such that one agency provides all EMS services within the municipality's boundaries. We identify 86 such contracting municipalities, where 56 different EMS providers operate. About 19\% of agencies are community-based (mostly integrated with local fire departments), 27\% are hospital-based, and the remaining 54\% are large private ambulance companies. EMS agencies integrated into and operated by hospitals may have different approaches to prehospital care due to closer 
medical supervision. Similarly, paramedics working for a large private multi-state company may have access to different training standards, equipment, and operate under more stringent protocols compared to a small, local fire-based agency. In the analysis, we therefore include EMS contracting area fixed effects as well as information about EMS provider type (i.e. private vs. hospital-based vs. fire-based) to account for those instances of switching between provider types, when municipalities change the type of provider with which they contract. As mentioned above, the analysis is conducted separately for trauma and medical incidents, which differ in scene and protocol.

\section{Results}

We provide summary statistics for medical and trauma runs in our data, broken by shift structure, in Tables 3a and 3b. In particular, these report the six different dependent variables of interest (total out-of-hospital time, on-scene time, response time, transport time, number of procedures, and minutes-per-procedure) along with key scene, provider, and patient characteristics.

Paramedics on 24-hour shifts tend to have shorter out-of-hospital times compared with their 12 hour shift counterparts for both trauma and medical runs (35.17 versus 36.20 minutes for trauma incidents and 35.33 versus 35.86 minutes for medical incidents). These differences arise from longer on-scene and transport times among paramedics on shorter shifts, though they are mitigated by shorter response times in both medical and trauma incidents. In addition, paramedics on 24-hour shifts undertake 0.2 more pre-hospital interventions in trauma incidents 
than their shorter shift counterparts, and each procedure is performed 1.33 minutes faster. This relationship is reversed for medical incidents, with those on 12-hour shifts initiating 0.1 more procedures and performing them slightly faster than those on longer shifts.

Among trauma incidents, those on long shifts see 2.7 percentage points more motor vehicle crashes, but 1.8 less falls. This helps explain the discrepancies in incident locations: long shifters are 3.6 and 3.1 percentage points more likely to attend scenes on county roads and state/federal highways, respectively, but are 3.5 and 3.2 percentage points less likely to be dispatched to incidents located on city streets and other locations (usually residences and nursing homes), respectively.

Figures $2 \mathrm{a}$ and $2 \mathrm{~b}$ show the total out-of-hospital time by hour of day for trauma and medical runs in Mississippi between 2001 and 2005. These graphs are unadjusted representations of the difference-in-differences approach described in the statistical analysis section. Specifically, they show mean pre-hospital durations by hour of the day, for paramedics on 24-hour (solid line) and 12-hour (dotted line) shifts. The (unadjusted) difference-in-differences estimate can roughly be read from the charts as the pre- to post-midnight change in performance that occurs among paramedics on 24-hour shifts minus that of paramedics on 12-hour shifts. The charts are on different scales, as there is much less variability in total out-of-hospital time in medical incidents, for which there are almost four times as many observations as there are for trauma. ${ }^{7}$

\footnotetext{
${ }^{7}$ Note that more than half of trauma incidents involve motor vehicle crashes, which may occur far from urban centers (and therefore require longer travel times) and in complex environments in terms of lighting, weather, and accessibility to victims (and therefore require more time spent on scene). This is another reason for the greater variability in total out-of-hospital time for trauma incidents compared with medical ones.
} 
Nonetheless, both charts suggest some deterioration in performance late at night among both short- and long-shifters, though this decline appears steeper among 24-hour paramedics.

Figures $2 \mathrm{a}$ and $2 \mathrm{~b}$ also highlight the substantial differences between short- and long-shifters. For instance, at baseline, it appears that 24-hour shifters are considerably more expeditious during business hours than their 12-hour counterparts. For trauma incidents, paramedics on long shifts are almost 2 minutes faster at delivering trauma patients to the hospital around noon or 1PM. For medical incidents, this gap is closer to 48 seconds. However, while the long-shifters are on average quicker during the day, this relationship is reversed late in their shift (12am-6am). Although these are observations based on covariate-unadjusted charts, the disparities suggest that there is non-negligible selection into 24-hour shifts, and that controlling for unobserved paramedic heterogeneity may be important.

As discussed below, the late-night reversals of performance may be mediated by factors other than fatigue. We therefore consider two additional performance indicators that are arguably more sensitive to paramedic fatigue: the number of pre-hospital procedures performed on-scene and minutes per procedure, with the latter conditioned on at least one procedure being performed. Figures $3 a$ and $3 b$ are analogous to Figures $2 a$ and $2 b$, and present the number and speed of procedures by hour of day separately for trauma and medical incidents. Particularly for trauma, the 24-hour shifters initiate almost 0.3 more procedures during the daytime than their short-shift counterparts, but this gap closes quickly starting around 7PM and reverses, such that, by midnight, the long-shifters perform 0.1 fewer procedures per incident. Although 
these differences are unadjusted cell means, they are consistent with fatigue accounting for the decline in paramedic performance.

\section{IV.1 Random Assignment}

To explore the possibility of nonrandom assignment of paramedics to incidents, we regress patient demographics, call type, medical symptoms, trauma injury and scene characteristics on paramedic shift structure according to specifications that mirror those of the difference-indifference analysis. In Table 4, we report the coefficients on the indicator for treatment (24 hour shift) and the interaction term ( 24 hour shift $x$ late at night). The upper panel reports results for medical incidents and the lower panel reports results for trauma incidents. Both panels report results for three models: the first includes paramedic, contract area, and hour of day fixed effects, as well as driver shift structure; the second adds controls for time off between the end of the previous shift and the start of the current one; the third model includes controls for the EMT's tenure. The results suggest that paramedic shift structure is unrelated to most patient and scene characteristics across all models. In the few instances (i.e. medical incidents occurring on county roads or trauma incidents involving patients in the "other race/ethnicity" category) in which the coefficient on the interaction between shift structure and incidents occurring between midnight and $6 \mathrm{AM}$ has some statistical significance, the magnitudes of the coefficients are extremely small. 


\section{IV.2 Difference-in-Differences Analysis}

Table 5 provides the results of the difference-in-differences analysis, controlling for paramedic fixed effects and upwards of 200 scene, patient, and EMT characteristics (as discussed in Section III). This level of saturation makes it highly unlikely that systematic differences across scenes which are correlated with shift length are responsible for the deterioration in EMT's performance towards the end of long shifts, compared to their performance towards the end of shorter shifts. For each model, we report the coefficient estimate on the interaction between an indicator for whether the paramedic is working a 24 hour shift and an indicator for whether the call occurs between midnight and 6 AM (i.e. $\gamma$ in equation (1)). In addition, we also report the estimate of $\phi$, the coefficient on the 24-hour shift "treatment" indicator as a check on the validity of the empirical strategy. In particular, since all models are estimated with paramedic fixed effects, the coefficient $\phi$ is identified from changes over time in a given paramedic's shift lengths; i.e. from switching between 12 -hour and 24-hour shifts. While shift structure may vary, we would not expect a paramedic's baseline performance to change as a result of this variation; in other words, we do not expect paramedics to alter their EMS practice with shift structure. The estimates of $\phi$ are thus reported as a test of this premise. Rejecting the null that $\phi=0$ would suggest that paramedics engage in potentially different EMS practice according to whether they are on long or short shifts and might raise questions as to the validity of the empirical strategy.

The first row of Table 5 indicates that paramedics on 24-hour shifts appear to be just under a minute slower in getting to the scene of medical or trauma emergencies between midnight and 6AM. For instance, conditional on incident characteristics, it takes paramedics when they are on 
24-hour shifts on average 0.94 additional minutes to arrive to the scene of a trauma incident towards the end of their shift, compared with when they are on shorter shifts. While the difference in their time spent on-scene is indistinguishable from zero, these paramedics take an additional 26 seconds $\left(=60^{*} 0.4373\right)$ transporting medical patients to the hospital. Aggregating across all time markers, trauma and medical patients appear to experience delays between a minute and a minute and eight seconds in total out-of-hospital time when a paramedic on a long shift is dispatched to their scene relative to when that same paramedic is scheduled for a 12-hour shift.

Nonetheless, the results along the margins of time markers may be difficult to interpret as being solely attributable to fatigue. First, paramedics are not exclusively responsible for producing first response and transport times, which might be more readily attributed to the driver of the ambulance unit. All of our models control for the driver's shift structure, certification level, tenure in years, and hours of inactivity before the beginning of their current shift. Moreover, the effects on first response time in particular may not be attributable to fatigue if EMS agencies accommodate the longer shifts by not requiring on-call paramedics to remain at the station late at night (such that they are being dispatched from their homes, say, rather than from a central location). Alternatively, they may be asleep when they receive such late night calls, and may thus be slower to get into the ambulance as a result. Although this is clearly a legitimate cost of long shifts, it is not fatigue from sustained wakefulness per se that drives it. 
These late-night effects of long shifts are not limited to EMS time markers as the number and speed of procedures performed on-scene are also affected in trauma incidents. Paramedics on 24 hour shifts engage in 0.18 (or $8.5 \%$ ) fewer procedures in the closing hours of their shifts, which helps explain why no effect was detected in on-scene time: no discernible difference in on-scene time is achieved by performing pre-hospital interventions more infrequently towards the end of long shifts. To distinguish whether these results are driven by the extensive vs. intensive margins of pre-hospital interventions, we separately study the likelihood that any procedure is performed at all, and the number of procedures conditional on initiating at least one procedure. Thus, we first estimate analogous difference-in-difference models first on an indicator for whether procedures were performed at all, then on the number of procedure conditional on this indicator equaling one. The results in Table 4 indicate that for trauma, the intensive margin appears to be driving the results: conditional on performing at least one procedure, paramedics on long shifts engage in 0.24 (or 11\%) fewer interventions. ${ }^{8}$

It is worth noting that no such selection on prehospital procedures is detected for medical incidents. Ex ante, this may make sense since EMS responses to medical emergencies are standardized to a much greater degree than in trauma incidents. Paramedic training and certification dictates specific responses and interventions for cardiac events, for instances,

\footnotetext{
${ }^{8}$ In more than $96 \%$ of cases, there is a single emergency medical technician certified as EMT-paramedic and a driver (certified as either an EMT-driver or an EMT-basic). In less than one percent of incidents, the unit is composed of two paramedics. Since only the paramedic is certified to perform the procedures recorded in our data, this measure number of procedures - is a margin along which fatigue can be more credibly attributed to the paramedic.
} 
whereas trauma incidents are much more unpredictable and less standardized. As such, there is more room for paramedic discretion in treating trauma patients.

Finally, as mentioned above, we also report the estimate of the coefficient associated to the indicator for long shifts. Comfortingly, it is indistinguishable from zero in the majority of models, with the only exceptions being in trauma for transport time and minutes per procedure. The estimates imply that, all else constant, when paramedics are scheduled for long shifts, their transport times are on average 13 seconds longer, and pre-hospital procedures are performed on average 9 seconds faster. While the driver with whom the paramedic is paired may account for the longer transport times, the reduction in minutes per procedure suggests that paramedics may hurry their procedures during long shifts.

\section{IV.3 Dose-Response Analysis}

The difference-in-differences approach provides a useful and simple framework for studying the effects of shift structure. It is not, however, without shortcomings. First, the identification comes from the timing of calls (midnight to 6AM), rather than from the duration of shifts directly. Second, focusing on calls between midnight and 6AM as the relevant time window for studying fatigue is arbitrary. Lastly, to the extent that any deterioration in performance is gradual as the shift progresses (even over short shifts), the difference-in-differences approach coarsely averages over this relationship. These observations call for a dose-response analysis. 
In the current context, the difficulty with undertaking such an analysis is that the precise shift structure of paramedics, and when shifts begin in particular, is not observed. We merely observe each paramedic's first incident after a long period of absence from the data. For instance, suppose that a paramedic started her shift at 7AM but that her first call (say an interfacility transfer) didn't come until 8:15AM. From the researcher's perspective, the 7AM start time is unobservable. Without further assumptions, all that is known is that her shift started before 8:15 AM. For any given incident, her duration in the current shift can thus be written:

$$
\begin{aligned}
& d_{i s 1}=u_{i s} ; \\
& d_{i s 2}=d_{i s 1}+\left(T_{i s 2}-T_{i s 1}\right) ; \\
& \ldots ; \\
& d_{i s k}=d_{i s(k-1)}+\left(T_{i s k}-T_{i s(\mathrm{k}-1)}\right) .
\end{aligned}
$$

where $d_{i s k}$ is the time elapsed in paramedic $i$ 's sth shift as of incident $k$, to which she was dispatched at time $T_{i s k}$. All terms in the above expressions are observable in MEMSIS except $u_{i s,}$ a non-negative random variable that embodies the delay from the time her shift started to her first incident.

One approach is to ignore $u_{\text {is }}$ and to study durations beyond the first one in each shift, treating the first run as the beginning of each shift and to estimate paramedic fixed effects models as done above in the difference-in-differences framework. However, doing so ignores the fact that the resulting measures of shift duration are left-censored versions of the truth. By exploiting only within-paramedic variation, this fixed effects approach would correlate deviations in performance from the paramedic mean with corresponding deviations in shift durations, which are randomly and differentially left-censored across shifts within paramedic. As discussed in 
Rigobon and Stoker (2009), this results in estimates of the parameter of interest that are biased away from zero.

Given that we have already constructed shifts, an alternative approach is to adopt a shift fixed effects approach, which effectively differences out the unobserved $u_{i s,}$ thereby overcoming the censoring problem. By specifying a flexible function of duration in shift, we can allow its relationship to performance to be arbitrarily nonlinear. In addition, rather than using variation only in shift structure that arises from paramedics switching between short and long shifts, this approach exploits all of the variation in the data, including changes in duration within short shifts. For instance, the estimated dose-response relationship at hour 7 exploits those incidents of both 12- and 24-hour shifters that occurred in their $7^{\text {th }}$ hour on duty. This is the approach adopted here, where we estimate models with a $6^{\text {th }}$ order polynomial in shift duration of the following form:

$$
y_{i s p}=\alpha_{i s}+\sum_{m=1}^{6} \lambda_{m} d_{i s p}^{m}+\mathbf{X}_{i s p}^{\prime} \Pi+\varepsilon_{i s p}
$$

where $\alpha_{i s}$ is a (paramedic $i \times$ shift $s$ ) fixed effect, $d_{i s p}$ is as defined above, and $\boldsymbol{X}_{\text {isp }}$ are the usual incident, patient, and provider characteristics. Rather than reporting estimates of the $\lambda_{m}$ coefficients, we plot estimates of and 95\% confidence intervals for $\sum_{m=1}^{6} \hat{\lambda}_{m} d^{m}$ for $d=0,1,2, \ldots, 24$ for the number of procedures, the likelihood that at least one procedure is performed, the number of procedures conditional on at least one being performed, and total out-of-hospital time in Figures 4a (Trauma Incidents) and 4b (Medical Incidents). For trauma incidents, the dose- 
response pattern over the 24-hour interval is distinguishable from zero for the number of procedures performed on scene, and the effects are sizeable: all else equal, by the $12^{\text {th }}$ hour of a shift, paramedics perform one less procedure than at the start of the shift, with more than twice that drop by the $24^{\text {th }}$ hour $\left(1^{\text {st }}\right.$ panel in Figure $\left.4 \mathrm{a}\right)$. An examination of the extensive and intensive margins reveals that this drop is driven entirely by the extensive margin: at hours 12 and 24, paramedics are 30 and 60 percentage points less likely to perform any procedures at all relative to the first incidents in their shift ( $2^{\text {nd }}$ panel versus $3^{\text {rd }}$ panel in Figure $\left.4 a\right)$.

For medical incidents (Figure 4b), a nonlinear relationship is estimated for total out-of-hospital time $\left(4^{\text {th }}\right.$ panel in Figure $\left.4 \mathrm{~b}\right)$, with a statistically significant incline starting in the $17^{\text {th }}$ hour of a shift. At the $24^{\text {th }}$ hour, paramedics take upwards of 0.8 minutes to deliver patients to definitive care, which is roughly consistent with the difference-in-differences estimates reported in Table 4. In contrast to the results of Table 4 and to the intuition provided above on limited paramedic discretion in medical incidents, there does appear to be a relationship between the number of procedures paramedics perform and the length of their shift. The $1^{\text {st }}$ panel in Figure $4 \mathrm{~b}$ indicates that the number of procedures in medical incidents also declines throughout a shift, though the magnitude is muted compared to trauma. By their $12^{\text {th }}$ and $24^{\text {th }}$ hours in a shift, paramedics perform 0.06 and 0.11 fewer pre-hospital procedures, respectively, during medical incidents. The $2^{\text {nd }}$ and $3^{\text {rd }}$ panels of Figure $4 \mathrm{~b}$ provide some suggestive evidence that this decline in procedures results from declines along both the extensive and intensive margins. At hours 12 and 24, paramedics are 1.1 and 1.5 percentage points less likely to perform any procedures at all than at the beginning of their shift, during the course of observationally equivalent incidents. In 
addition, conditional on performing at least one procedure, paramedics undertake 0.13 fewer interventions by their $24^{\text {th }}$ hour than at the beginning of their shifts.

Lastly, it is worth noting that detecting a relationship along the margin of the number of procedures in medical incidents in the dose-response approach but not in the difference-indifferences approach is not necessarily inconsistent. In particular, the baselines are very different in the two approaches. In the difference-in-differences, deteriorations are detected as differences in average performance over the last 6 hours of long shifts relative to the first 18 hours, benchmarked to the corresponding differences observed among short shifters. As such, the baseline is the degree of deterioration between night and day among 12-hour shifters. In the dose-response analysis, the baseline is instead the average performance on the very first run of a shift, across all paramedics and across all shift structures. Furthermore, the two methods exploit different sources of variation, one being within-paramedic variation in shift structure, the other being within-shift variation in time-on-call, and the former averages over the slope of the relationship in the latter. As a result, if there is a negative slope in the relationship between performance and time-in-shift over the first 18 hours of the shift, the difference-in-differences will miss it entirely, assigning one overall average to it. In the case of number of procedures performed in medical incidents (top left panel of Figure 4b.), for instance, the difference-indifferences misses the sharp decline in procedures that appears to occur between the $7^{\text {th }}$ and $18^{\text {th }}$ hours on call. As a result, the leveling off in procedures that occurs beyond the $18^{\text {th }}$ hour does not turn up statistically distinguishable from a baseline which is already pulled downwards by the most dramatic portion of the decline in procedures. 


\section{Discussion}

While this is primarily a measurement paper, the impact of shift structure on workers' performance is an issue that has received increasing attention by regulatory bodies in manufacturing and service industries. However, a review of the literature reveals that the evidence of longer shifts on, for example, hospitals' performance is mixed at best. In our study, we offer an evaluation of the effect of shift structure and shift length on workers' performance, by using objective process measures capturing speed and activity, to examine the effect of shift structure on paramedic performance. Our results are consistent with the hypothesis that fatigue plays a role in the decline of the performance of paramedics at the end of 24 hour shifts. Our study is, to our knowledge, the largest scale observational study to estimate the effect of shift structure on workers' performance, using a dataset that is collected in real time by paramedics responding to calls.

There are several possible limitations to our study. We focused on well-accepted process measures, EMS intervals, as markers of paramedic performance. While shorter out-of-hospital time intervals represent a potentially important factor in survival (Feero et al, 1995; Nichol et al, 1996; Sampalis et al, 2002, IOM, 2007), outcome markers such as patient mortality may be better in evaluating the effect of longer transport times on patient outcomes. Because we do not have inpatient data, we were unable to evaluate the process measure itself in our data. In addition, we constructed paramedic shifts based on the timing of each paramedic's appearance in 
MEMSIS. While prone to measurement error, our strategies provide conservative estimates as, if anything, the resulting classification tends to erroneously label paramedics who are truly on 24 hour shifts as 12 hour shifters, thus blurring the line between the treatment and control groups and biasing our results towards the null.

In conclusion, we found that paramedics working longer shifts exhibit poorer performance towards the end of their shift (midnight to $6 \mathrm{AM}$ ), as measured by prehospital intervals and the number of prehospital interventions, compared to their own performance when working 12 hour (or less) shifts. In addition, we estimated dose-response relationships between shift length and performance that overcome data limitations resulting from censored shift durations. These revealed steep declines in the numbers of prehospital interventions, particularly for trauma incidents. We argue that this margin in particular provides the most convincing piece of evidence that fatigue plays a role in the performance of paramedics on long shifts. Given the mixed results in the literature on the link between shift duration and worker performance, our study of a large-scale observational setting contributes to the evidence by showing that performance deteriorates with shift length, the underlying mechanism likely being fatigue. Clinical studies of fatigue have shown that it is associated with slower reaction times, lapses of attention, poor motor function, and memory loss (Lambert, 2005), which our results particularly along the margin of number of procedures - are consistent with. ${ }^{9}$

\footnotetext{
${ }^{9}$ A person awake for 24 hours has the same reaction time and critical thinking ability as a well-rested individual with a blood alcohol level of 0.10 percent, a level considered legally drunk in all US states.
} 
Ultimately, a firm's choice of shift structure is the result of balancing business requirements (Mayshar and Halevy, 1997), employee desires (Kostiuk, 1990), and regulatory objectives (Coleman, 1995). One of these objectives is minimal health and safety standards for employees working extended hours, such as the 2010 recommendations by the ACGME to cap shift length at 16 hours for interns (Nasca et al., 2010). While over 80 percent of employees work a daytime schedule, more than 21 million wage and salary workers in the U.S. (17.7 percent) work alternate shifts that fall at least partially outside of the daytime shift range (McMenamin, 2007). ${ }^{10}$

So why do people work extended hours? Neoclassical theory would suggest that individuals will work longer hours (for example, back-to-back shifts) to supplement their income when their marginal rate of substitution between leisure and income is below the wage rate. ${ }^{11}$ Consistent with this argument, wage differentials were found to affect workers' shift choice (Lanfranchi et al., 2002; Presser, 2003). In particular, there is evidence of self-selection in the choice to work extended hours, as workers with low potential daytime salary were found to be more likely to choose night work to supplement their earnings (Kostiuk, 1990).

Consistent with findings of compensating differentials, the health and safety consequences for employees working extended hours, are likely to be internalized. However, as we find in this

\footnotetext{
${ }^{10}$ Similar findings were reported for Canada (Williams, 2008) and European countries (Le Bihan and Martin, 2004).

${ }^{11}$ In addition, there is some evidence for a "shift premium" (Lanfranchi et al., 2002).
} 
paper, working longer shifts may impose a negative externality on others. In health care, the concern is that extended work hours could negatively impact patients' health and well-being. To counterbalance such effects, health care providers are held legally responsible for the harm they impose on patients due to professional negligence. Evidence suggests that health care providers react to malpractice pressure by offering more procedures and tests, a behavior often labeled "defensive medicine" (Kessler and McClellan, 1996). However, there is no evidence that health care institutions react to such pressure by shortening shifts or discouraging the practice of back-to-back shifts.

The notion of increasing marginal utility of leisure (with the number of hours worked) is central to the underlying tradeoff between the utility from consumption and the utility from leisure. Nevertheless, holding labor supply constant, diminishing marginal utility of income does not suggest that individuals would prefer to work shorter shifts. For example, imagine that work hours per week are the relevant interval for labor supply decisions. Clearly, individuals working 48 hours per week can do so in two 24-hour shifts or in four 12-hour shifts, depending on their preferences and the flexibility offered by firms (Altman and Golden, 2007). ${ }^{12}$

Without the ability to conceptually link shift structure with labor supply decisions, neoclassical theory provides little guidance for understanding employees' preferences for organizing their work schedule. One such link could come from the idea that shorter shifts provide greater

\footnotetext{
${ }^{12}$ EMS in Mississippi is organized based on sole provider contracts; therefore, paramedics residing in a given contracting area may not have much flexibility in affecting the shift structure.
} 
flexibility for altering the number of hours worked in a given week (e.g. through the practice of back-to-back shifts). This would certainly apply if individuals held a single job. However, anecdotal evidence suggests that paramedics working 24-hours shifts have two or three days off between shifts and are more likely to hold a second job (Kuehl, 2002). Therefore, the link between shift structure and labor supply decisions is not obvious. ${ }^{13}$

Finally, EMS often relies on volunteers; this may suggest that there are non-pecuniary benefits to working as a paramedic (e.g. serving the community, saving lives, or from thrills embedded in the delivery of emergency care). Non-pecuniary benefits were found to be associated with labor supply (Lazear, 1991; Freedman, 1997; Akerlof and Kranton, 2005; Farzin, 2009), but there is no reason to think that these are associated with workforce scheduling.

\footnotetext{
${ }^{13}$ From a measurement perspective, concerns regarding such selection (and others discussed earlier in the paper) highlight the importance of our within paramedic approach.
} 


\section{References}

Akerlof, George A., and Rachel E. Kranton 2005. "Identity and the Economics of Organizations." Journal of Economic Perspectives, 19(1): 9-32.

Altman M, Golden L (2007), The Economics of Flexible Work Scheduling: Theoretical Advances and Contemporary Paradoxes, in Lisa A. Keister (ed.) Workplace Temporalities (Research in the Sociology of Work, Volume 17), Emerald Group Publishing Limited, pp.313-341

Arnedt JT, Owens J, Crouch M, Stahl J, Carskadon MA. "Neurobehavioral performance of residents after heavy night call vs after alcohol ingestion." Journal of the American Medical Association. 2005;294(9):1025-1033

Carr BG, Brachet T, David G, Duseja R, Branas CC. “The Time Cost of Prehospital Intubation and Intravenous Access in Trauma Patients." Prehospital Emergency Care. 2008; 12(3): 327-332.

Coleman, R.M. 1995. The 24 hour Business. Maximizing Productivity through the Round-theClock Operations. Amacom, New York.

David G, Brachet T. "Retention, Learning by Doing, and Performance in Emergency Medical Services." Health Services Research, 2009; 44(3): 902-925.

Farzin, Y.H. “The effect of non-pecuniary motivations on labor supply" Quarterly Review of Economics and Finance, 2009, 49(4), 1236-1259.

Feero S, Hedges JR, Simmons E, and Irwin L. “Does Out-of-Hospital EMS Time Affect Trauma Survival?" American Journal of Emergency Medicine 13(2), March 1995.

Freeman, Richard B, 1997. "Working for Nothing: The Supply of Volunteer Labor," Journal of Labor Economics, University of Chicago Press, vol. 15(1), pages S140-66.

Institute of Medicine (IOM): Committee on the Future of Emergency Care in the United States Health System. 2007. Emergency Medical Services: At the Crossroads. The National Academies Press.

Kessler D, and McClellan M. Do Doctors Practice Defensive Medicine? Quarterly Journal of Economics Vol. 111, No. 2 (May, 1996), pp. 353-390

Kohn LT, Corrigan JM, Donaldson MS. To Err Is Human: Building a Safer Health System. Washington, DC: National Academy Press; 2000.

Kostiuk, P.F. 1990. Compensating differentials for shift work. Journal of Political Economy 98, 10551075. 
Kuehl, Alexander E. 2002. Prehospital Systems and Medical Oversight, 3rd Edition, Dubuque, Iowa: Kendall/ Hunt Publishing Company.

Lambert C. 2005. Deep into Sleep. The Harvard Magazine, July-August 2005.

Lanfranchi, J, H Ohlsson, and A Skalli. Compensating wage differentials and shift work preferences, Economics Letters, Volume 74, Issue 3, February 2002, Pages 393-398,

Lazear, Edward P. 1991. "Labor Economics and the Psychology of Organizations." Journal of Economic Perspectives, Spring, 5:2, pp. 89-110.

Le Bihan, B., \& Martin, C. (2004). Atypical working hours: Consequences for childcare arrangements. Social Policy and Administration, 38 , 565-590.

Mayshar J and Halevy Y, "Shiftwork," Journal of Labor Economics: Vol. 15, No. 1, Part 2, January 1997, pp. S198-S222.

McMenamin TM, 2007. "A time to work: recent trends in shift work and flexible schedules", Monthly Labor Review, 130(12), 3-15.

Nasca TJ, Day SH, Amis ES. The new recommendations on duty hours from the ACGME Task Force. New England Journal of Medicine 2010; 363: e3-e3

Nichol, Graham, Allan Detsky, Ian Stiell, Keith O'Rourke, George Wells, and Andreas Laupacis. "Effectiveness of Emergency Medical Services for Victims of Out-of-Hospital Cardiac Arrest: A Meta Analysis" Annals of Emergency Medicine, June 1996. 17(6):700-710.

Presser, HB. 2003. Race-ethnic and gender differences in nonstandard work shifts. Work and Occupations, 30, 412-439.

Rigobon R, Stoker T. "Bias from Censored Regressors," Journal of Business and Economic Statistics, 27(3), pp. 340-353, 2009.

Sampalis JS, Lavoie A, Williams JI, Mulder DS, Kalina M. “Impact of on-site care, pre-hospital time, and level of inhospital care on survival in severely injured patients." Journal of Trauma-Injury Infection \& Critical Care 34(2):252-261, February 1993.

Veasey S, Rosen R, Barzansky B, Rosen I, Owens J. Sleep loss and fatigue in residency training: a reappraisal. Journal of the American Medical Association. 2002;288(9):1116-1124.

Williams, C. 2008. Work-life balance of shift workers. Perspectives. Ottawa, Ontario: Statistics Canada. 
Figure 1a.

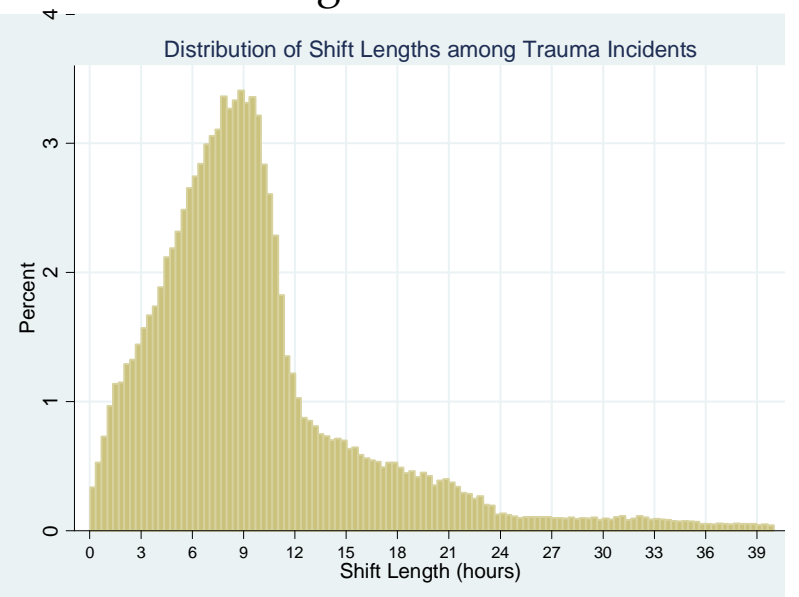

Figure 1c.

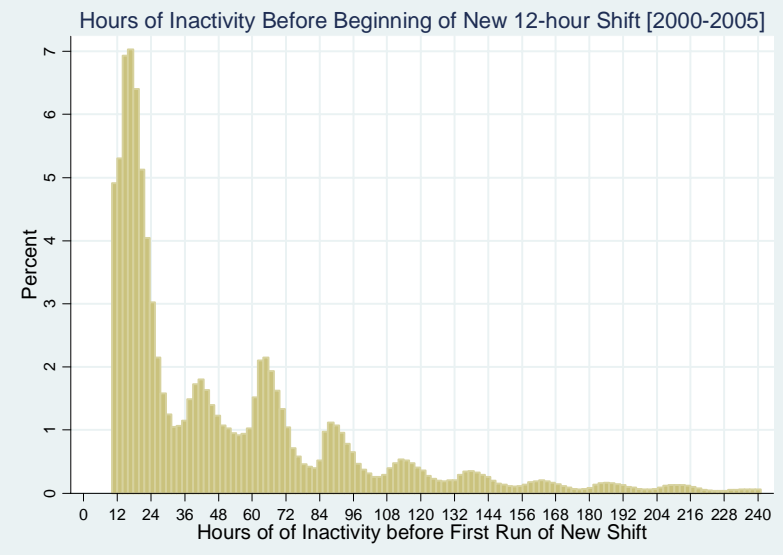

Figure 1e.

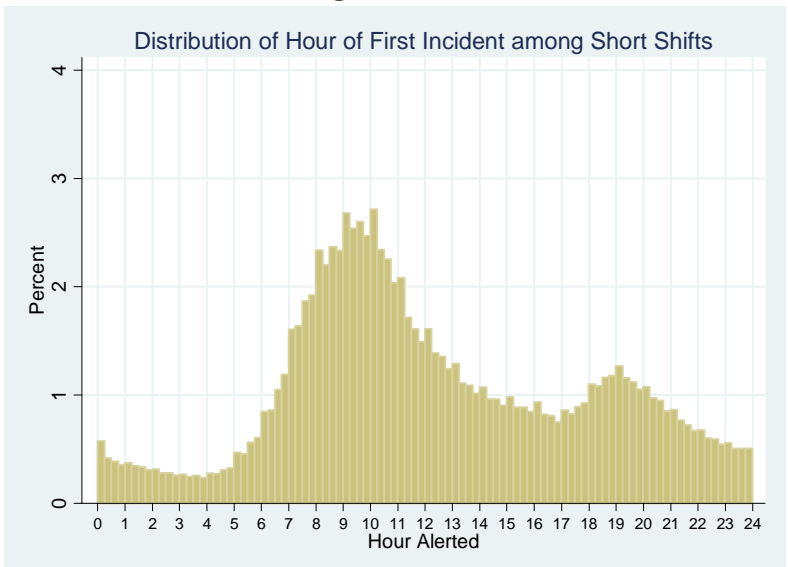

Figure 1b.

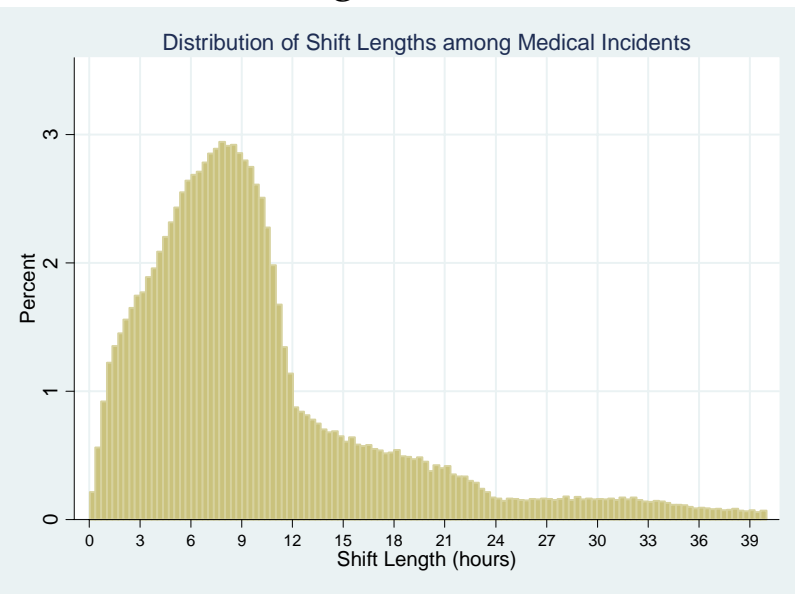

Figure 1d.

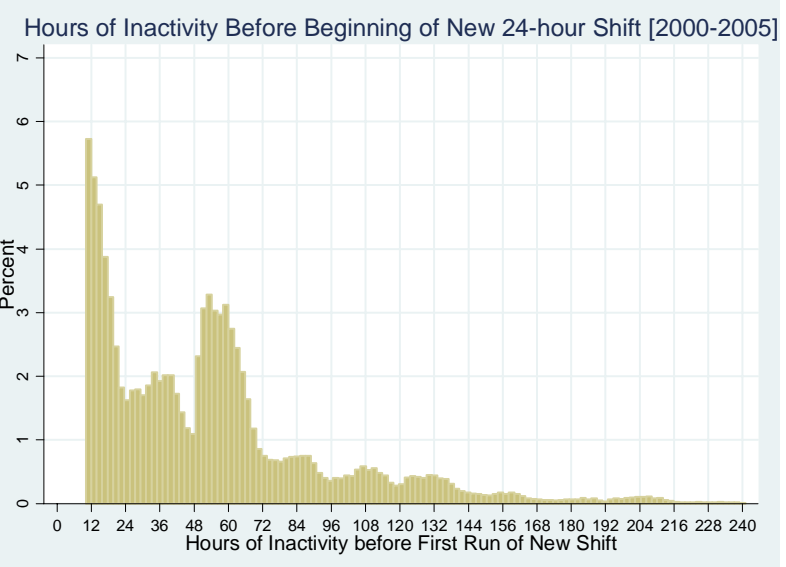

Figure 1f.

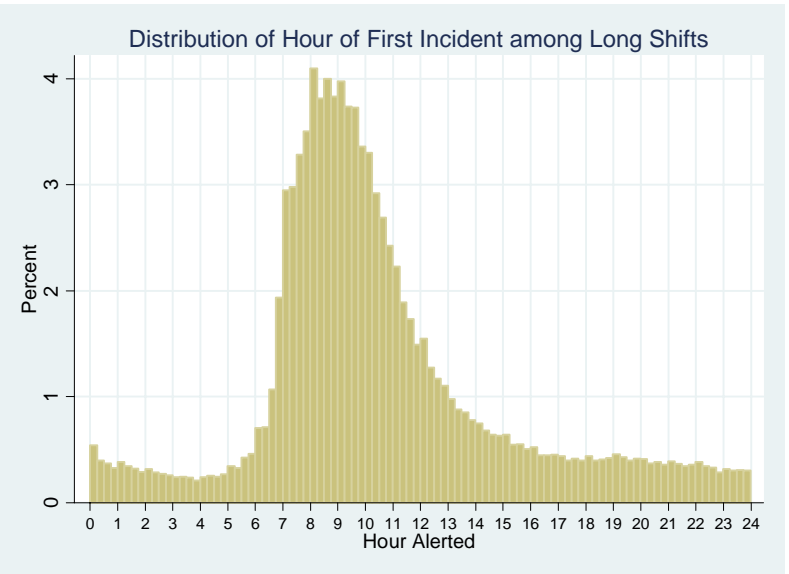


Figure 2a.

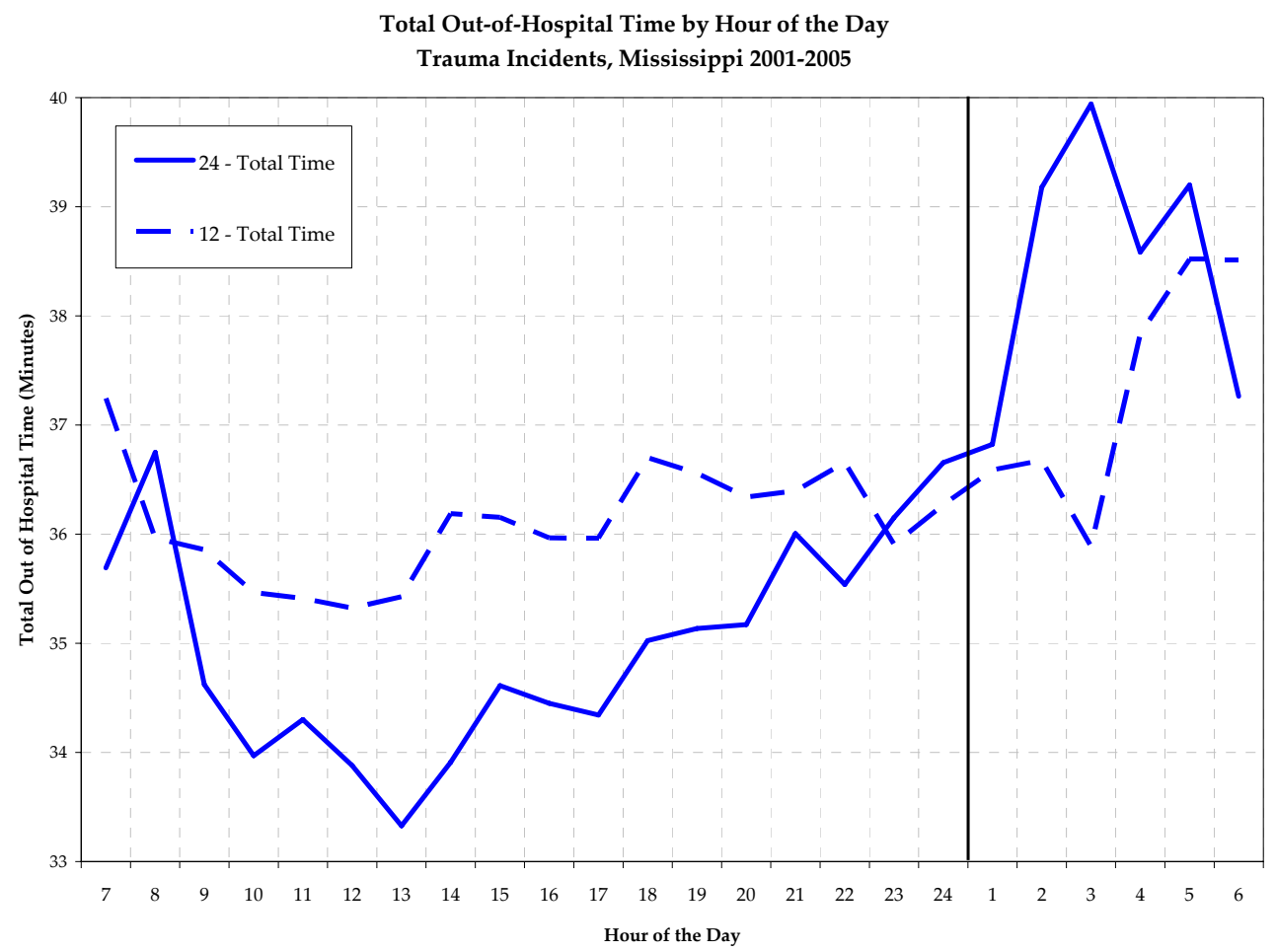

Figure 2b.

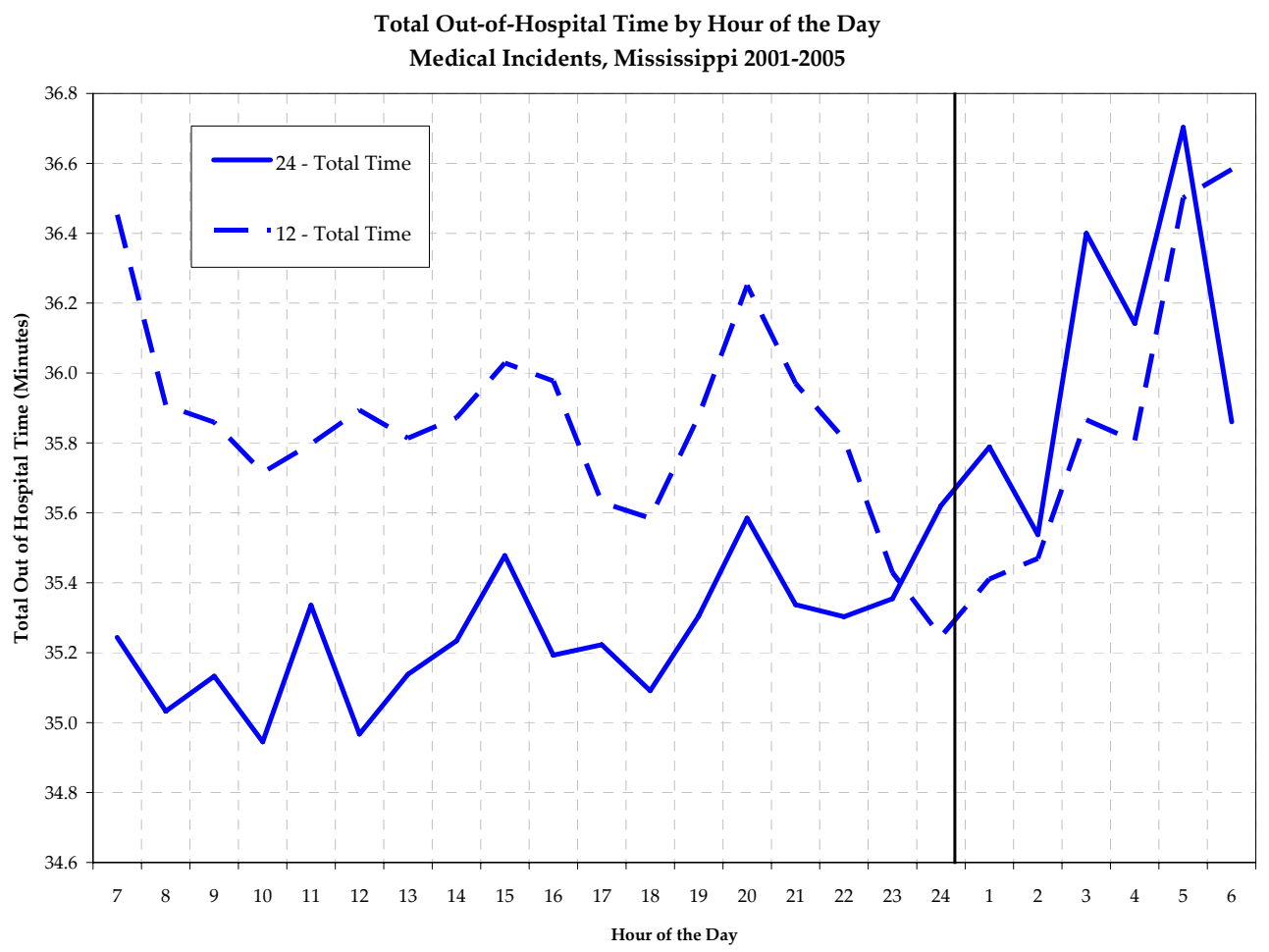


Figure 3a.

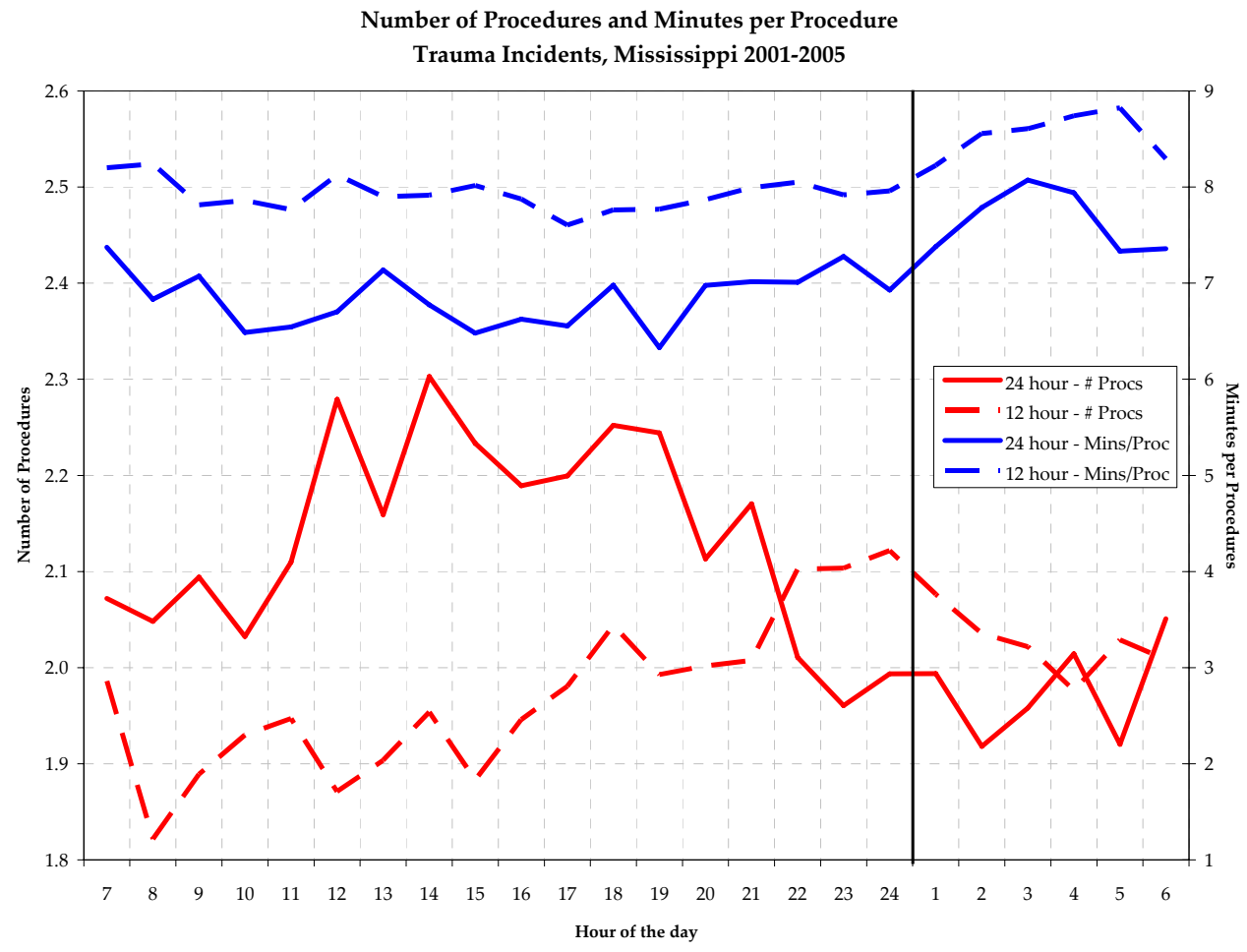

Figure $3 b$.

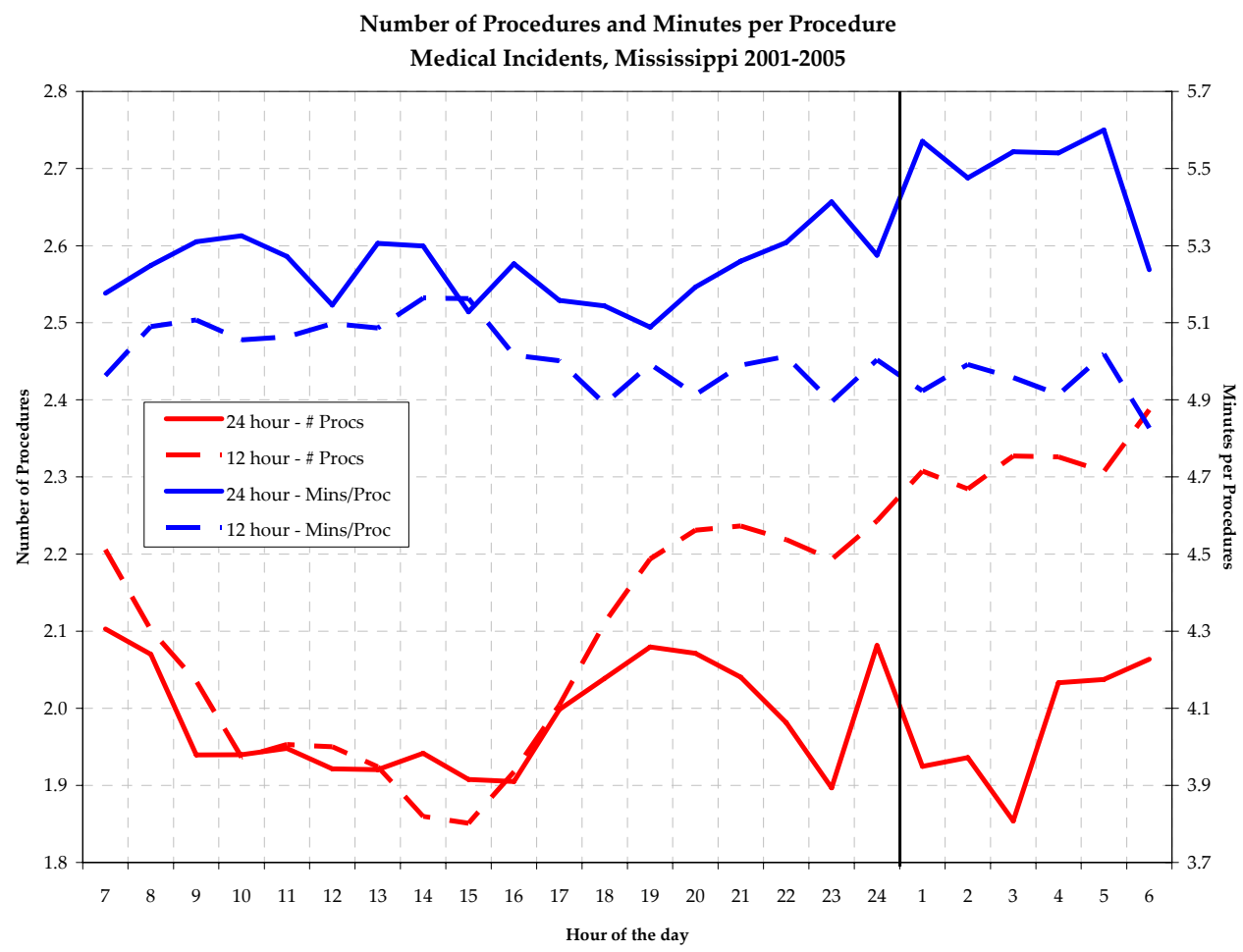


Figure 4a. Trauma Incidents: Shift Fixed Effects Models with $6^{\text {th }}$ Order Polynomial in Time in Shift
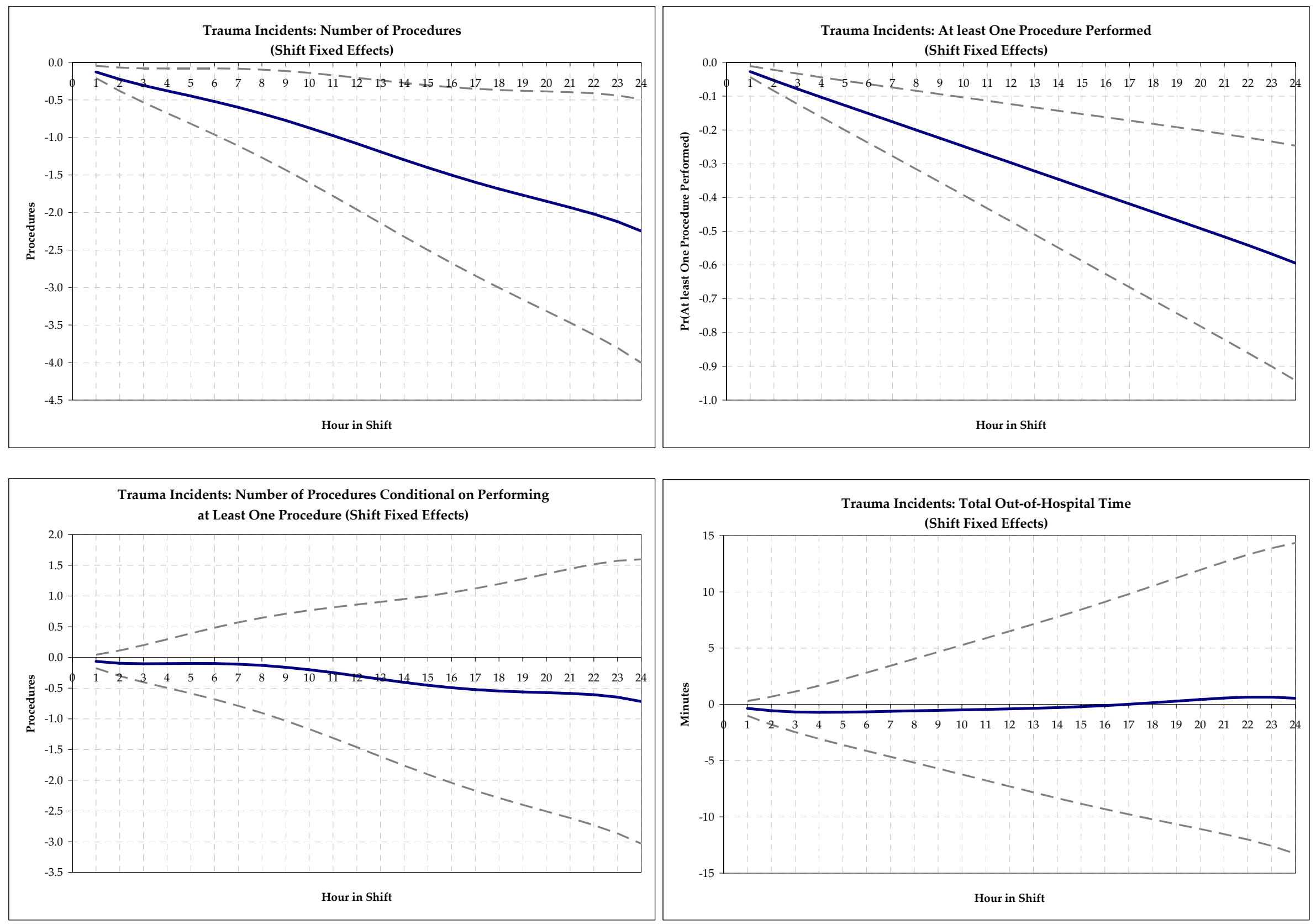
Figure 4b. Medical Incidents: Shift Fixed Effects Models with $6^{\text {th }}$ Order Polynomial in Time in Shift
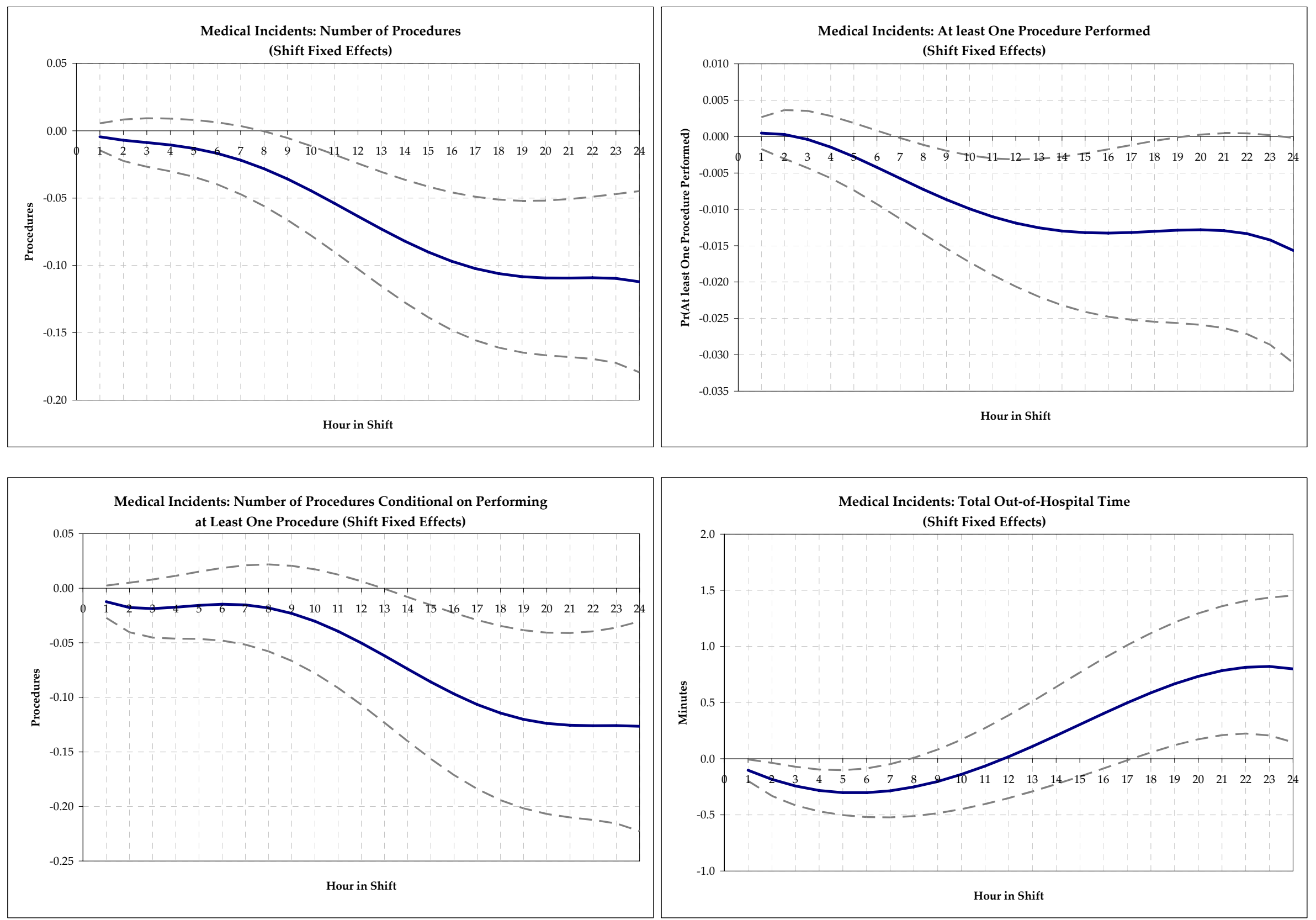


\section{Table 1.}

\begin{tabular}{|c|c|c|c|c|}
\hline \multirow[b]{2}{*}{ Year } & \multicolumn{2}{|c|}{ TRAUMA } & \multicolumn{2}{|c|}{ MEDICAL } \\
\hline & $\begin{array}{c}\text { \% Incidents Served by } \\
\text { a Paramedic on a 24- } \\
\text { Hour Shift }\end{array}$ & $\begin{array}{l}\% \text { of Paramedic Shifts } \\
\text { that are } 24 \text {-hour }\end{array}$ & $\begin{array}{c}\text { \% Incidents Served by } \\
\text { a Paramedic on a 24- } \\
\text { Hour Shift }\end{array}$ & $\begin{array}{c}\text { \% of Paramedic Shifts } \\
\text { that are 24-hour }\end{array}$ \\
\hline 2001 & $23.4 \%$ & $20.7 \%$ & $24.0 \%$ & $18.4 \%$ \\
\hline 2002 & $27.2 \%$ & $24.3 \%$ & $27.2 \%$ & $21.4 \%$ \\
\hline 2003 & $29.2 \%$ & $25.9 \%$ & $29.3 \%$ & $22.6 \%$ \\
\hline 2004 & $29.3 \%$ & $25.7 \%$ & $29.4 \%$ & $22.6 \%$ \\
\hline 2005 & $32.0 \%$ & $27.8 \%$ & $32.4 \%$ & $24.4 \%$ \\
\hline Total & $28.2 \%$ & $24.8 \%$ & $28.5 \%$ & $21.9 \%$ \\
\hline
\end{tabular}




\section{Table 2.}

\begin{tabular}{|c|c|c|c|}
\hline \multirow[b]{2}{*}{ Year } & \multicolumn{3}{|c|}{$\begin{array}{l}\text { \% Trauma Incidents Attended by a Paramedic } \\
\text { on a } 24-\text { Hour Shift }\end{array}$} \\
\hline & $\begin{array}{l}\text { Public/ } \\
\text { Fire-Based }\end{array}$ & Hospital-Based & $\begin{array}{l}\text { Private For- } \\
\text { Profit Corp. }\end{array}$ \\
\hline 2001 & $42.6 \%$ & $19.3 \%$ & $19.0 \%$ \\
\hline 2002 & $43.9 \%$ & $20.8 \%$ & $24.9 \%$ \\
\hline 2003 & $44.8 \%$ & $23.5 \%$ & $26.5 \%$ \\
\hline 2004 & $43.9 \%$ & $23.6 \%$ & $26.8 \%$ \\
\hline 2005 & $46.9 \%$ & $27.9 \%$ & $28.9 \%$ \\
\hline Total & $44.4 \%$ & $22.9 \%$ & $25.3 \%$ \\
\hline
\end{tabular}

\begin{tabular}{ccc}
\hline \multicolumn{3}{c}{$\begin{array}{c}\text { M Medical Incidents Attended by a Paramedic } \\
\text { on a 24-Hour Shift }\end{array}$} \\
$\begin{array}{c}\text { Public } / \\
\text { Fire-Based }\end{array}$ & Hospital-Based & $\begin{array}{c}\text { Private For- } \\
\text { Profit Corp. }\end{array}$ \\
\hline $37.7 \%$ & $18.4 \%$ & $22.2 \%$ \\
$42.1 \%$ & $21.1 \%$ & $25.6 \%$ \\
$41.9 \%$ & $22.1 \%$ & $28.9 \%$ \\
$42.7 \%$ & $23.9 \%$ & $28.2 \%$ \\
$46.1 \%$ & $25.5 \%$ & $32.1 \%$ \\
\hline $42.0 \%$ & $22.2 \%$ & $27.7 \%$ \\
\hline
\end{tabular}


Table 3a. Summary Statistics for Trauma Incidents

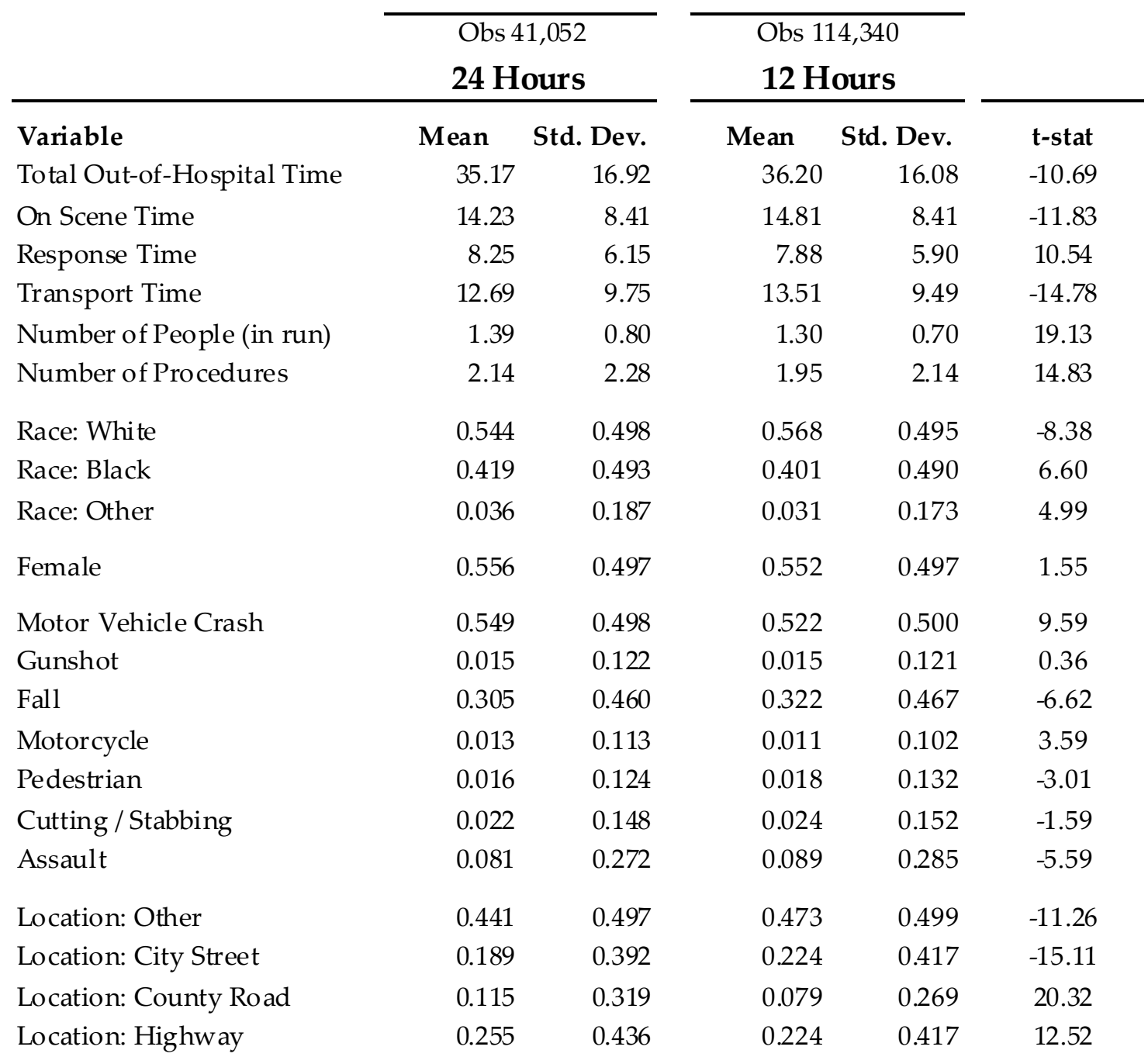


Table 3b. Summary Statistics for Medical Incidents

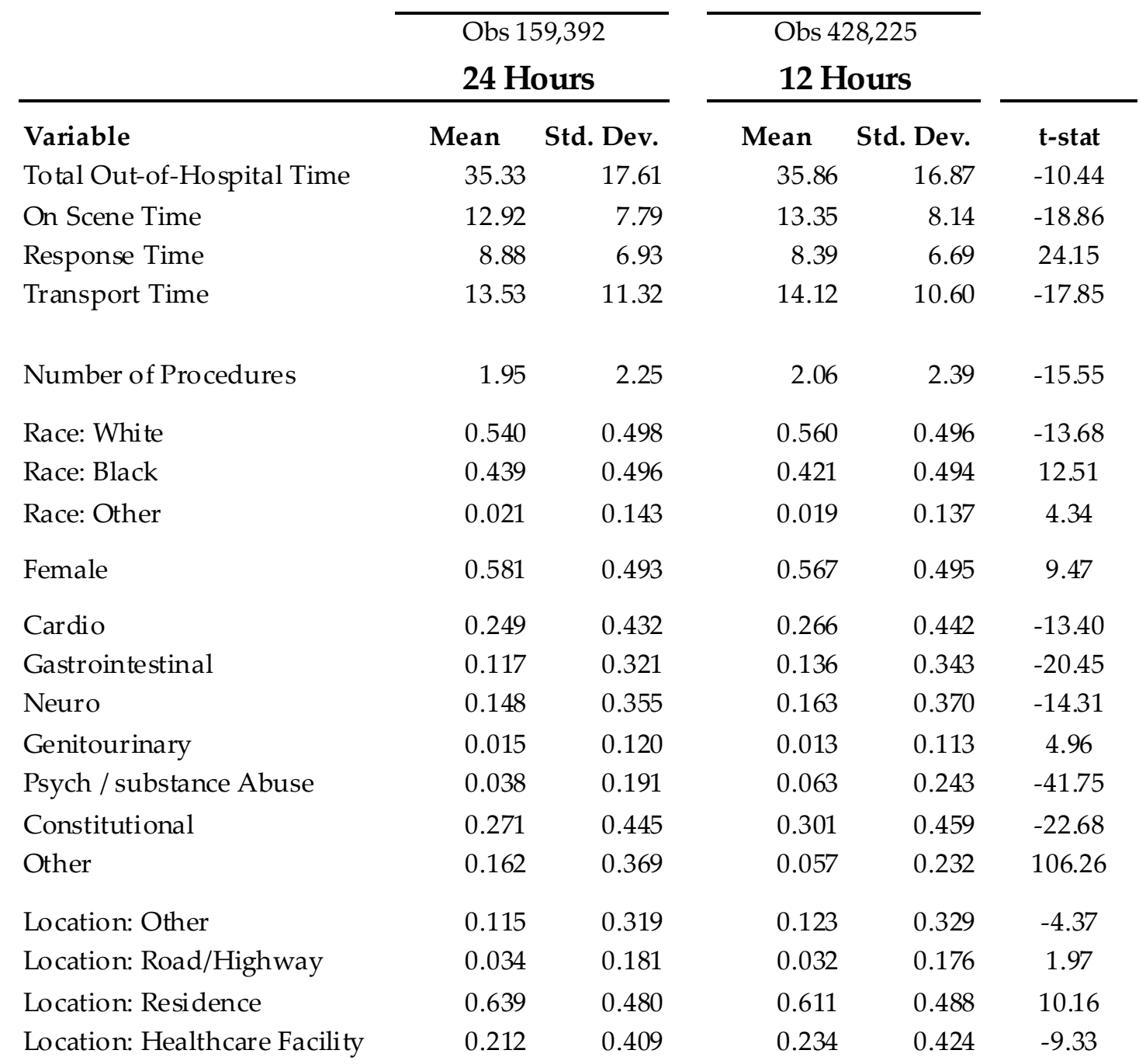


Table 4: Random Assignment Regressions with Paramedic, Contract Area, and Hour of the Day Fixed Effects

\begin{tabular}{|c|c|c|c|c|c|c|c|c|c|c|c|c|c|}
\hline \multirow{2}{*}{$\begin{array}{l}\text { Medical Incidents } \\
(\mathrm{N}=521,087)\end{array}$} & \multicolumn{4}{|c|}{ Patient Demographics } & \multicolumn{2}{|c|}{ Location } & \multicolumn{4}{|c|}{ Incident Type (Medical) } & \multirow[b]{2}{*}{ Breathing Diff } & \multicolumn{2}{|r|}{ Sympthoms } \\
\hline & White & Black & Other Race & Female & County Road & Highway & Drowning & Smoke & Poison & Overdose & & Chest Pain & Hemorrhage \\
\hline \multicolumn{14}{|l|}{ Model [1] } \\
\hline Treatment & $\begin{array}{c}0.0000 \\
{[0.0026]}\end{array}$ & $\begin{array}{c}-0.0007 \\
{[0.0026]}\end{array}$ & $\begin{array}{c}0.0007 \\
{[0.0008]}\end{array}$ & $\begin{array}{c}0.0020 \\
{[0.0025]}\end{array}$ & $\begin{array}{c}-0.0003 \\
{[0.0004]}\end{array}$ & $\begin{array}{c}-0.0001 \\
{[0.0007]}\end{array}$ & $\begin{array}{c}0.0001 \\
{[0.0002]}\end{array}$ & $\begin{array}{c}-0.0001 \\
{[0.0001]}\end{array}$ & $\begin{array}{c}-0.0001 \\
{[0.0002]}\end{array}$ & $\begin{array}{c}0.0001 \\
{[0.0004]}\end{array}$ & $\begin{array}{c}0.0010 \\
{[0.0018]}\end{array}$ & $\begin{array}{c}-0.0002 \\
{[0.0014]}\end{array}$ & $\begin{array}{l}-0.0008 \\
{[0.0005]}\end{array}$ \\
\hline Treatment $x$ Post & $\begin{array}{c}0.0079 \\
{[0.0072]}\end{array}$ & $\begin{array}{c}-0.0063 \\
{[0.0072]}\end{array}$ & $\begin{array}{l}-0.0016 \\
{[0.002]}\end{array}$ & $\begin{array}{c}0.0093 \\
{[0.0079]}\end{array}$ & $\begin{array}{c}-0.0022 \\
{[0.0013]^{*}}\end{array}$ & $\begin{array}{c}-0.0002 \\
{[0.0017]}\end{array}$ & $\begin{array}{c}-0.0010 \\
{[0.0007]}\end{array}$ & $\begin{array}{c}0.0006 \\
{[0.0006]}\end{array}$ & $\begin{array}{c}-0.0002 \\
{[0.0006]}\end{array}$ & $\begin{array}{c}0.0006 \\
{[0.0017]}\end{array}$ & $\begin{array}{c}0.0073 \\
{[0.0059]}\end{array}$ & $\begin{array}{c}0.0073 \\
{[0.0046]}\end{array}$ & $\begin{array}{c}0.0019 \\
{[0.0017]}\end{array}$ \\
\hline \multicolumn{14}{|l|}{ Model [2] } \\
\hline Treatment & $\begin{array}{c}-0.0001 \\
{[0.0026]}\end{array}$ & $\begin{array}{c}-0.0007 \\
{[0.0026]}\end{array}$ & $\begin{array}{c}0.0007 \\
{[0.0008]}\end{array}$ & $\begin{array}{c}0.0021 \\
{[0.0025]}\end{array}$ & $\begin{array}{c}-0.0003 \\
{[0.0004]}\end{array}$ & $\begin{array}{c}0.0000 \\
{[0.0007]}\end{array}$ & $\begin{array}{c}0.0001 \\
{[0.0002]}\end{array}$ & $\begin{array}{c}-0.0001 \\
{[0.0001]}\end{array}$ & $\begin{array}{c}-0.0001 \\
{[0.0002]}\end{array}$ & $\begin{array}{c}0.0000 \\
{[0.0004]}\end{array}$ & $\begin{array}{c}0.0010 \\
{[0.0018]}\end{array}$ & $\begin{array}{c}-0.0002 \\
{[0.0014]}\end{array}$ & $\begin{array}{c}-0.0008 \\
{[0.0005]}\end{array}$ \\
\hline Treatment $x$ Post & $\begin{array}{c}0.0078 \\
{[0.0073]}\end{array}$ & $\begin{array}{c}-0.0063 \\
{[0.0072]}\end{array}$ & $\begin{array}{l}-0.0016 \\
{[0.002]}\end{array}$ & $\begin{array}{c}0.0092 \\
{[0.0079]}\end{array}$ & $\begin{array}{c}-0.0022 \\
{[0.0013]^{*}}\end{array}$ & $\begin{array}{l}-0.0002 \\
{[0.0017]}\end{array}$ & $\begin{array}{l}-0.0010 \\
{[0.0007]}\end{array}$ & $\begin{array}{c}0.0006 \\
{[0.0006]}\end{array}$ & $\begin{array}{c}-0.0002 \\
{[0.0006]}\end{array}$ & $\begin{array}{c}0.0006 \\
{[0.0017]}\end{array}$ & $\begin{array}{c}0.0071 \\
{[0.0059]}\end{array}$ & $\begin{array}{c}0.0073 \\
{[0.0046]}\end{array}$ & $\begin{array}{c}0.0019 \\
{[0.0017]}\end{array}$ \\
\hline \multicolumn{14}{|l|}{ Model [3] } \\
\hline Treatment & $\begin{array}{c}0.0000 \\
{[0.0026]}\end{array}$ & $\begin{array}{l}-0.0007 \\
{[0.0026]}\end{array}$ & $\begin{array}{c}0.0008 \\
{[0.0008]}\end{array}$ & $\begin{array}{c}0.0021 \\
{[0.0025]}\end{array}$ & $\begin{array}{c}-0.0003 \\
{[0.0004]}\end{array}$ & $\begin{array}{l}-0.0001 \\
{[0.0007]}\end{array}$ & $\begin{array}{c}0.0000 \\
{[0.0002]}\end{array}$ & $\begin{array}{c}-0.0001 \\
{[0.0001]}\end{array}$ & $\begin{array}{c}-0.0001 \\
{[0.0002]}\end{array}$ & $\begin{array}{c}0.0000 \\
{[0.0004]}\end{array}$ & $\begin{array}{c}0.0012 \\
{[0.0018]}\end{array}$ & $\begin{array}{l}-0.0001 \\
{[0.0014]}\end{array}$ & $\begin{array}{c}-0.0008 \\
{[0.0005]}\end{array}$ \\
\hline Treatment $x$ Post & $\begin{array}{c}0.0078 \\
{[0.0072]}\end{array}$ & $\begin{array}{c}-0.0062 \\
{[0.0072]}\end{array}$ & $\begin{array}{l}-0.0015 \\
{[0.002]}\end{array}$ & $\begin{array}{c}0.0093 \\
{[0.0079]}\end{array}$ & $\begin{array}{c}-0.0022 \\
{[0.0013]^{*}}\end{array}$ & $\begin{array}{l}-0.0002 \\
{[0.0017]}\end{array}$ & $\begin{array}{c}-0.0010 \\
{[0.0007]}\end{array}$ & $\begin{array}{c}0.0006 \\
{[0.0006]}\end{array}$ & $\begin{array}{c}-0.0002 \\
{[0.0006]}\end{array}$ & $\begin{array}{c}0.0006 \\
{[0.0017]}\end{array}$ & $\begin{array}{c}0.0073 \\
{[0.0059]}\end{array}$ & $\begin{array}{c}0.0074 \\
{[0.0046]}\end{array}$ & $\begin{array}{c}0.0019 \\
{[0.0017]}\end{array}$ \\
\hline Trauma Incidents & \multicolumn{4}{|c|}{ Patient Demographics } & \multicolumn{2}{|c|}{ Location } & \multicolumn{4}{|c|}{ Incident Type (Trauma) } & \multicolumn{3}{|c|}{ Trauma Type and Injured } \\
\hline$(\mathrm{N}=143,708)$ & White & Black & Other Race & Female & County Road & Highway & MVC & Gunshot & Fall & Assault & Dislocated Arm & Back Pain & Burn (Face) \\
\hline \multicolumn{14}{|l|}{ Model [1] } \\
\hline Treatment & $\begin{array}{l}0.0039 \\
{[0.006]}\end{array}$ & $\begin{array}{l}-0.0038 \\
{[0.006]}\end{array}$ & $\begin{array}{l}-0.0001 \\
{[0.002]}\end{array}$ & $\begin{array}{c}0.0036 \\
{[0.0055]}\end{array}$ & $\begin{array}{c}-0.0017 \\
{[0.0042]}\end{array}$ & $\begin{array}{c}-0.0021 \\
{[0.0055]}\end{array}$ & $\begin{array}{c}0.0030 \\
{[0.0059]}\end{array}$ & $\begin{array}{c}0.0000 \\
{[0.0012]}\end{array}$ & $\begin{array}{c}-0.0016 \\
{[0.0053]}\end{array}$ & $\begin{array}{c}0.0022 \\
{[0.0029]}\end{array}$ & $\begin{array}{c}-0.0019 \\
{[0.0016]}\end{array}$ & $\begin{array}{l}-0.0058 \\
{[0.004]}\end{array}$ & $\begin{array}{c}0.0000 \\
{[0.0003]}\end{array}$ \\
\hline Treatment $x$ Post & $\begin{array}{c}0.0187 \\
{[0.0162]}\end{array}$ & $\begin{array}{c}-0.0055 \\
{[0.0159]}\end{array}$ & $\begin{array}{c}-0.0132 \\
{[0.0074]^{*}}\end{array}$ & $\begin{array}{c}-0.0075 \\
{[0.0163]}\end{array}$ & $\begin{array}{l}-0.0064 \\
{[0.0123]}\end{array}$ & $\begin{array}{l}-0.0022 \\
{[0.0145]}\end{array}$ & $\begin{array}{c}-0.0072 \\
{[0.0182]}\end{array}$ & $\begin{array}{c}-0.0041 \\
{[0.0058]}\end{array}$ & $\begin{array}{c}0.0147 \\
{[0.0151]}\end{array}$ & $\begin{array}{c}-0.0012 \\
{[0.0138]}\end{array}$ & $\begin{array}{c}0.0015 \\
{[0.0046]}\end{array}$ & $\begin{array}{c}0.0157 \\
{[0.0112]}\end{array}$ & $\begin{array}{l}-0.0002 \\
{[0.001]}\end{array}$ \\
\hline \multicolumn{14}{|l|}{ Model [2] } \\
\hline Treatment & $\begin{array}{l}0.0036 \\
{[0.006]}\end{array}$ & $\begin{array}{l}-0.0036 \\
{[0.006]}\end{array}$ & $\begin{array}{l}0.0000 \\
{[0.002]}\end{array}$ & $\begin{array}{c}0.0036 \\
{[0.0055]}\end{array}$ & $\begin{array}{c}-0.0018 \\
{[0.0042]}\end{array}$ & $\begin{array}{c}-0.0021 \\
{[0.0056]}\end{array}$ & $\begin{array}{c}0.0030 \\
{[0.0059]}\end{array}$ & $\begin{array}{c}0.0000 \\
{[0.0012]}\end{array}$ & $\begin{array}{c}-0.0016 \\
{[0.0053]}\end{array}$ & $\begin{array}{c}0.0022 \\
{[0.0029]}\end{array}$ & $\begin{array}{c}-0.0020 \\
{[0.0016]}\end{array}$ & $\begin{array}{l}-0.0058 \\
{[0.004]}\end{array}$ & $\begin{array}{c}0.0000 \\
{[0.0003]}\end{array}$ \\
\hline Treatment $x$ Post & $\begin{array}{c}0.0185 \\
{[0.0163]}\end{array}$ & $\begin{array}{c}-0.0053 \\
{[0.0159]}\end{array}$ & $\begin{array}{c}-0.0132 \\
{[0.0074]^{*}}\end{array}$ & $\begin{array}{c}-0.0081 \\
{[0.0163]}\end{array}$ & $\begin{array}{c}-0.0063 \\
{[0.0123]}\end{array}$ & $\begin{array}{c}-0.0022 \\
{[0.0145]}\end{array}$ & $\begin{array}{c}-0.0075 \\
{[0.0182]}\end{array}$ & $\begin{array}{c}-0.0041 \\
{[0.0058]}\end{array}$ & $\begin{array}{c}0.0148 \\
{[0.0151]}\end{array}$ & $\begin{array}{c}-0.0010 \\
{[0.0138]}\end{array}$ & $\begin{array}{c}0.0015 \\
{[0.0046]}\end{array}$ & $\begin{array}{c}0.0157 \\
{[0.0112]}\end{array}$ & $\begin{array}{l}-0.0002 \\
{[0.001]}\end{array}$ \\
\hline \multicolumn{14}{|l|}{ Model [3] } \\
\hline Treatment & $\begin{array}{l}0.0036 \\
{[0.006]}\end{array}$ & $\begin{array}{l}-0.0036 \\
{[0.006]}\end{array}$ & $\begin{array}{l}0.0000 \\
{[0.002]}\end{array}$ & $\begin{array}{c}0.0037 \\
{[0.0055]}\end{array}$ & $\begin{array}{c}-0.0017 \\
{[0.0042]}\end{array}$ & $\begin{array}{c}-0.0022 \\
{[0.0055]}\end{array}$ & $\begin{array}{c}0.0030 \\
{[0.0059]}\end{array}$ & $\begin{array}{c}0.0000 \\
{[0.0012]}\end{array}$ & $\begin{array}{l}-0.0016 \\
{[0.0053]}\end{array}$ & $\begin{array}{c}0.0022 \\
{[0.0029]}\end{array}$ & $\begin{array}{c}-0.0019 \\
{[0.0016]}\end{array}$ & $\begin{array}{l}-0.0056 \\
{[0.004]}\end{array}$ & $\begin{array}{c}0.0000 \\
{[0.0003]}\end{array}$ \\
\hline Treatment $x$ Post & $\begin{array}{c}0.0184 \\
{[0.0162]}\end{array}$ & $\begin{array}{c}-0.0053 \\
{[0.0159]}\end{array}$ & $\begin{array}{c}-0.0132 \\
{[0.0074]^{*}}\end{array}$ & $\begin{array}{c}-0.0080 \\
{[0.0163]}\end{array}$ & $\begin{array}{c}-0.0062 \\
{[0.0123]}\end{array}$ & $\begin{array}{c}-0.0022 \\
{[0.0145]}\end{array}$ & $\begin{array}{c}-0.0076 \\
{[0.0182]}\end{array}$ & $\begin{array}{c}-0.0041 \\
{[0.0058]}\end{array}$ & $\begin{array}{c}0.0149 \\
{[0.0151]}\end{array}$ & $\begin{array}{c}-0.0010 \\
{[0.0138]}\end{array}$ & $\begin{array}{c}0.0015 \\
{[0.0046]}\end{array}$ & $\begin{array}{c}0.0161 \\
{[0.0112]}\end{array}$ & $\begin{array}{l}-0.0002 \\
{[0.001]}\end{array}$ \\
\hline
\end{tabular}

Note: All models control for Paramedic, contract area, and hour of day fixed effects, as well as for the driver's shift structure. Standard errors are clustered at the paramedic level. Model [1]: No controls fc between End of Last Shift and Start of Current One or EMT Tenure. Model [2]: Controls for Time Off between End of Last Shift and Start of Current One. Model [3]: Controls for Both Time Off between End Start of Current One and EMT Tenure. Similar results were obtained using age categories, year, month, and day dummies, as well as for additional call, location, destination, trauma type, and medical sy1 results are not reported due to space constraints and are available from the authors. 


\section{Table 5 - Difference-in-Differences Analysis}

\section{Outcome}

\begin{tabular}{|c|c|c|c|c|c|}
\hline \multirow{2}{*}{ tcome } & & \multicolumn{2}{|c|}{ Trauma Incidents } & \multicolumn{2}{|c|}{ Medical Incidents } \\
\hline & & Coef & $\mathrm{SE}$ & Coef & $\mathrm{SE}$ \\
\hline \multirow{2}{*}{ First Response Time* } & $\mathrm{T}$ & 0.0812 & {$[0.07072]$} & 0.0107 & [0.03777] \\
\hline & $\mathrm{T} \times$ Post & 0.9427 & {$[0.20572]^{* * *}$} & 0.7323 & {$[0.11134]^{* * *}$} \\
\hline \multirow[t]{2}{*}{ On Scene Time* } & $\mathrm{T}$ & -0.1003 & [0.09489] & 0.0544 & {$[0.04338]$} \\
\hline & $\mathrm{T} \times$ Post & -0.2172 & [0.32279] & -0.0503 & [0.12455] \\
\hline \multirow[t]{2}{*}{ Transport Tiime } & $\mathrm{T}$ & 0.2252 & {$[0.10082]^{* *}$} & 0.0700 & [0.06906] \\
\hline & T $x$ Post & 0.0659 & {$[0.28038]$} & 0.4373 & {$[0.15146]^{* * *}$} \\
\hline \multirow[t]{2}{*}{ Out-of-Hospital Tiime } & $\mathrm{T}$ & 0.1825 & {$[0.17045]$} & 0.1299 & {$[0.09871]$} \\
\hline & $\mathrm{T} \times$ Post & 0.9937 & {$[0.53774]^{*}$} & 1.1458 & {$[0.25495]^{* * *}$} \\
\hline \multirow[t]{2}{*}{ Number of Procedures* } & $\mathrm{T}$ & 0.0213 & {$[0.02633]$} & 0.0106 & [0.01087] \\
\hline & $\mathrm{T} \times$ Post & -0.1825 & {$[0.07519]^{* *}$} & -0.0405 & [0.02906] \\
\hline \multirow[t]{2}{*}{ At Least One Procedure* } & $\mathrm{T}$ & -0.0043 & {$[0.00534]$} & 0.0048 & {$[0.00278]^{*}$} \\
\hline & $\mathrm{T} \times$ Post & -0.0014 & {$[0.0146]$} & -0.0086 & {$[0.00673]$} \\
\hline Number of Procedures* & $\mathrm{T}$ & 0.0327 & {$[0.02968]$} & 0.0080 & {$[0.01171]$} \\
\hline Conditional on at Least One & $\mathrm{T} \times$ Post & -0.2437 & {$[0.08595]^{* * *}$} & -0.0351 & {$[0.03366]$} \\
\hline \multirow[t]{2}{*}{ Minutes per Procedure* } & $\mathrm{T}$ & -0.1504 & {$[0.07621]^{* *}$} & 0.0198 & [0.03109] \\
\hline & $\mathrm{T} \times$ Post & 0.3578 & {$[0.2611]$} & 0.1013 & [0.08837] \\
\hline \multicolumn{2}{|c|}{$N$} & 143,708 & & 521,087 & \\
\hline \multicolumn{2}{|c|}{$N$ (conditional on $>1$ procedure) } & 99,828 & & 291,687 & \\
\hline
\end{tabular}

Trauma Incidents

Coef SE

99,828
Medical Incidents

291,687

Notes: Outcomes that are marked with an asterisk $\left(^{*}\right)$ do not control for procedures. $\mathrm{T}=\mathbf{1}$ (24-hour shift); Post $=\mathbf{1}$ (Midnight to $6 \mathrm{AM}$ ). Standard errors are clustered at the paramedic level. "**", "**", and "***" indicate significance at the $10 \%, 5 \%$, and $1 \%$ levels, respectively.

All models control for the certification levels of both the driver and paramedic (indicators for EMT-Driver, EMT-Basic, EMTIntermediate, EMT-Paramedic), their tenure in years, and their hours of inactivity before the beginning of the current shift. All models also control for EMS service area fixed effects, patient demographics (indicators for race, gender, and 12 age categories), location of incident (street, clinic, physician's office, farm, hospice, hospital, county road, industrial site, nursing home, office, public place, residence, restaurant, school, highway, other location), and hour of day, day of week, month of year, and year indicators. We also control for the driver's shift structure in the same (difference-in-differences) manner as the paramedic, though only the latter's coefficients are reported.

Trauma models additionally control for indicators of type of trauma (falls, gunshot wounds, cuts or stabbings, assaults, motor vehicle crashes, and motorcycle and pedestrian accidents), and injury characteristics (70 interactions of injured body part and injury type). Medical models control for indicators of incident type (e.g. cardiac event, drowning, poisoning, etc) and 32 indicators of patient symptoms. 